\title{
BEYOND GDP: IS THERE A LAW OF ONE SHADOW PRICE?
}

\author{
Fabrice Murtin, Romina Boarini, Juan Carlos Cordoba, and Marla Ripoll ${ }^{1}$
}

Abstract - This paper builds a welfare measure encompassing household disposable income, unemployment and longevity, while using two different sets of "shadow prices" for non-income variables. The valuations of vital and unemployment risks estimated from life satisfaction data ("subjective shadow prices") and those derived from model-based approaches and calibrated utility functions ("model-based shadow prices") are shown to be broadly consistent once a number of conditions are fulfilled. Subjective shadow prices appear to be inflated by the downward bias on the income variable in life satisfaction regressions conducted at the individual level, while the latter bias is largely removed when running regressions at the country level. On the other hand, model-based shadow prices are typically underestimated as: (i) the valuation of the unemployment risk is assumed to take place under the veil of ignorance (i.e. for a representative agent that has no information on her current or future unemployment situation); (ii) the standard model relies on a constant relative risk aversion utility function, which has no specific relative risk aversion parameter for unemployment and vital risks; (iii) the value of statistical life that is used in standard calibration pertains to the adult lifespan, while life expectancy at birth covers the entire lifetime.

Murtin: OECD Statistics Directorate and Sciences-Po Paris; Boarini: OECD Statistics Directorate; Cordoba: Iowa State University; Ripoll: University of Pittsburgh.

We thank Thomas Piketty, David de la Croix and Jaya Krishnakumar for helpful comments, as well as participants at seminars at the University of Geneva, the Paris School of Economics, Université Louvain-la-Neuve, and the Inter-American Development Bank. 


\section{Introduction}

IN the past few years the quest for measures of welfare alternative to GDP has become topical in many countries and in many circles (OECD, 2011). While the research community is far from having found the "Holy Grail", considerable progress has been made in assessing the pros and cons of various approaches, and in understanding what next steps are needed to overcome some of the limitations. This paper examines one approach increasingly seen as promising in the literature for its many good theoretical properties: the money-metric approach or income equivalent (Samuelson, 1956, 1961, 1974; Fleurbaey, 2009; Fleurbaey and Blanchet, 2013). Under this approach, nonincome dimensions of welfare, such as health and access to jobs, are "monetized" by computing the willingness to pay to achieve certain reference levels for these non-material goods.

The main challenge of the money-metric approach is to find a credible valuation of nonmaterial goods in a common money metric. Once the "shadow prices" of welfare determinants such as health, access to jobs, environment or personal security have been determined, it is then straightforward to construct an aggregate welfare measure. ${ }^{2}$ However, assessing credible shadow prices is a major difficulty that has not been overcome yet. In particular, there appears to be a gap between model-based approaches such as Becker et al. (2005) or Gaulier and Fleurbaey (2009), and economic studies that use life satisfaction or happiness data to infer the shadow prices of nonmaterial components. For example, Gaulier and Fleurbaey find that suppressing the risk of unemployment among OECD countries would be worth about $1 \%$ of national GDP per capita (Gaulier and Fleurbaey, 2009, Table 4). In contrast, the subjective cost of being personally unemployed represents an enormous proportion of individual income in life satisfaction studies (e.g.

2 See OECD (2013a) for a review of welfare dimensions. 
95\% of individual income in Boarini et al., 2012, as derived from Table 3 column 3; see also Clark and Oswald, 1994, and Frey and Stutzer, 2000). ${ }^{3}$

This paper aims to reconcile the existing evidence on the shadow prices of two particular risks, namely the mortality and unemployment risks, and to incorporate them into a measure of aggregate welfare. Specifically, we compare the "subjective shadow prices" of vital and unemployment risks assessed from life satisfaction data to those derived from a model-based approach, where a calibrated utility function is used to calculate "model-based shadow prices". We show that under certain conditions, the two sets of shadow prices are largely consistent.

In calculations of both model-based and subjective shadow prices (in what follows referred as "model-based and subjective approaches") the valuation of non-material goods is defined as the variation in income that compensates for the change in those goods (see Fleurbaey and Blanchet, 2013; Gaulier and Fleurbaey, 2009). However, the model-based and subjective approaches differ in the way they calculate compensating differentials in practice. The model-based approach postulates a particular utility function and then estimates some of its parameters using existing empirical evidence. For instance, Becker et al. (2005) use a constant relative risk aversion (henceforth CRRA) utility function with intercept and calibrate its intercept using estimates of the value of statistical life (Viscusi and Aldy, 2003). A similar approach is followed in Murphy and Topel (2005) and Hall and Jones (2007). We label this procedure as the "model-based approach", ${ }^{4}$ in the sense that it is based on a particular model of people's utility.

In the second approach, indirect utility is proxied by self-reported life satisfaction (or any other measure of happiness), as available from surveys. In practice, an econometric model of life

3 From Boarini et al. (2012) Table 9 Column 1, one similarly finds that setting the country unemployment rate to zero is equivalent to a $90 \%$ cut in individual income. Di Tella et al. (2001) and Stutzer and Lalive (2004) analyze the effect of general unemployment on life satisfaction and also find a considerable loss, but they do not include individual income in their micro-level regressions.

4 This label may be slightly misleading, as the parameters of the utility function are calibrated to figures that sometimes reflect preferences (such as the willingness-to-pay for lowering vital risk). Therefore this approach should not be viewed as a purely model-based assessment of individuals' welfare. 
satisfaction is estimated, and the subjective shadow prices of unemployment and longevity are computed as the ratio between their elasticity and the income elasticity. In other words, subjective shadow prices are the monetary amount that would increase life satisfaction as much as one percentage point reduction in unemployment or a one-year increase in longevity would do. The use of life satisfaction data to value non-material goods is common in numerous studies on housing conditions, environmental quality, employment or health (see Fujiwara, 2013, and Fujiwara and Campbell, 2011, for surveys), or several of the latter dimensions (Boarini et al., 2012). As this methodology is relying on subjective data, it is labelled as the "subjective approach".

The analysis in this paper yields three main findings. First, using 2005-2010 data from a sample of 31 OECD countries plus the Russian Federation, we find that life satisfaction regressions conducted at the individual level yield implausibly large subjective shadow prices for life expectancy and unemployment risk. This happens because the resulting income coefficient is biased downwards due to measurement error or unobserved heterogeneity that stem from the dataset at hand (nonofficial data and cross-sectional). It is possible to remove these effects by carrying out regressions with the dependent variable expressed as country average life satisfaction, and the independent variables are measured as country-level income (based on official data), unemployment and longevity; and including country fixed effects.

The second insight of our analysis is that standard model-based shadow prices for life expectancy and unemployment risks are probably too low due to two main reasons. One reason relates to the limitations of the CRRA utility function to adequately reflect preferences. Specifically, valuations of vital risk appear to be underestimated when using simple CRRA utility functions because CRRA assumes: a) that people are indifferent to the timing of resolution of their mortality risk; and b) that the marginal utility of survival is constant. A well-known recursive utility function that relaxes these two assumptions is the one proposed by Epstein-Zin and Weil (Epstein and Zin, 1989, 1991; and Weil, 1990). As shown in Cordoba and Ripoll (2013), the latter utility function is 
also the most relevant one for estimating longevity shadow prices in a sample that includes lowincome countries, because it is more consistent with international evidence on the value of statistical life relative to income. The second reason why model-based shadow prices tend to be low has to do with ex-ante valuations. For instance, in the case of unemployment, model-based approaches that rely on ex-ante evaluation of unemployment risks (namely "under a veil of ignorance") tend to underestimate it because they do not take into account individual's information about one's own labour market history. In reality, unemployed workers value reductions in unemployment risk much more than employed workers, a feature that that can be accounted for by allowing state contingent valuations.

Our third finding is that it is possible to reconcile subjective and model-based shadow prices for mortality and unemployment risks. Once subjective shadow prices have been adjusted downwards by correcting for measurement error and unobserved heterogeneity, they can be rationalized by the model-based approach that combines two elements. One is a generalized representation of Epstein-Zin and Weil preferences that nests both mortality and unemployment risks. This nested utility representation disentangles three different parameters, namely intertemporal substitution, mortality risk aversion, and unemployment risk aversion. While estimates of the elasticity of intertemporal substitution abound, we calibrate the mortality aversion parameter using information on the value of statistical life. We then illustrate the range of unemployment risk aversion parameters that make the model-based shadow price compatible with the subjective shadow price. The second important element is the computation of contingent, rather than ex-ante, valuations of unemployment risks. Contingent valuations in the model better capture the responses of individuals in life satisfaction surveys, since respondents are either employed or unemployed.

The remainder of the paper is organized as follows. Section 2 describes the data. Section 3 presents the subjective approach to compute shadow prices, while Section 4 develops the theoretical 
framework used for model-based valuation. Section 5 reports the calculated equivalent incomes for mortality and unemployment risks among OECD countries. Last section concludes.

\section{Data}

This section describes the data for a sample of 31 OECD countries plus one "key partner", namely the Russian Federation.

\section{A. Life Satisfaction, Income and Life Expectancy}

Life satisfaction data is extracted from the Gallup World Poll conducted in more than 150 countries since 2005. Life satisfaction is measured on a 0-10 scale and reflects the cognitive judgement by a person about life as a whole. As shown on Table 1, average life satisfaction varies between 4.8 in Hungary and 7.7 in Denmark, with a sample average of 6.6.

The Gallup survey also contains a household total income variable that is used in individuallevel regressions. In country-level regressions, an equivalized household disposable income variable borrowed from the OECD (2013b) is preferred, as it also includes in-kind transfers from the state. It is available over the $2005-2010$ period. Life expectancy at birth is taken from World Development Indicators database (World Bank, 2013). 
TABle 1. - Descriptive Statistics - 2009

\begin{tabular}{|c|c|c|c|c|c|c|}
\hline & $\begin{array}{c}\text { Average life } \\
\text { satisfaction } \\
0-10 \text { scale } \\
\end{array}$ & $\begin{array}{c}\text { Average disposable } \\
\text { household income } \\
\text { USD }\end{array}$ & $\begin{array}{c}\text { Life expectancy at } \\
\text { birth } \\
\text { years } \\
\end{array}$ & $\begin{array}{c}\text { Unemployment rate } \\
\text { per cent }\end{array}$ & $\begin{array}{c}\text { Effective } \\
\text { replacement rate } \\
\text { per cent }\end{array}$ & $\begin{array}{c}\text { Average duration of } \\
\text { unemployment spell } \\
\text { years }\end{array}$ \\
\hline AUS & 7.4 & 25581 & 81.5 & 5.7 & 40.9 & 0.31 \\
\hline AUT & 7.3 & 25817 & 80.1 & 4.8 & 61.1 & 0.59 \\
\hline BEL & 7.0 & 24519 & 79.7 & 8.0 & 56.0 & 1.10 \\
\hline CAN & 7.5 & 26351 & 80.7 & 8.4 & 45.4 & 0.21 \\
\hline $\mathrm{CHE}$ & 7.5 & 24850 & 82.0 & 4.2 & 63.2 & 1.20 \\
\hline $\mathrm{CHL}$ & 6.5 & 9443 & 78.8 & 10.0 & 14.2 & na \\
\hline CZE & 6.3 & 15825 & 77.1 & 6.8 & 51.1 & 1.36 \\
\hline DEU & 6.7 & 25590 & 79.8 & 7.8 & 67.1 & 1.00 \\
\hline DNK & 7.7 & 20281 & 78.6 & 6.1 & 62.2 & 0.48 \\
\hline ESP & 6.2 & 21345 & 81.5 & 18.1 & 50.1 & 0.83 \\
\hline EST & 5.1 & 12130 & 74.8 & 14.0 & 37.7 & 1.19 \\
\hline FIN & 7.6 & 21287 & 79.7 & 8.4 & 57.1 & 0.46 \\
\hline FRA & 6.3 & 25451 & 81.1 & 9.2 & 55.0 & 0.79 \\
\hline GBR & 6.9 & 25599 & 80.1 & 7.8 & 40.0 & 0.68 \\
\hline GRC & 6.0 & 19963 & 80.2 & 9.6 & 34.6 & 1.24 \\
\hline HUN & 4.8 & 11920 & 73.9 & 10.1 & 45.4 & 2.01 \\
\hline $\mathrm{IRL}$ & 7.0 & 23179 & 80.0 & 12.2 & 53.8 & 1.18 \\
\hline ITA & 6.3 & 20647 & 81.4 & 7.9 & 38.1 & 1.44 \\
\hline JPN & 5.8 & 21582 & 82.9 & 5.3 & 33.3 & 0.48 \\
\hline KOR & 5.6 & 15179 & 80.3 & 3.8 & 29.1 & na \\
\hline LUX & 7.1 & 32382 & 80.1 & 5.2 & 59.5 & 0.75 \\
\hline MEX & 7.0 & 9913 & 76.5 & 5.4 & 13.4 & 0.84 \\
\hline NLD & 7.6 & 23590 & 80.5 & 3.7 & 59.7 & 0.76 \\
\hline NOR & 7.6 & 27376 & 80.8 & 3.2 & 57.8 & 0.42 \\
\hline NZL & 7.3 & 16311 & 80.7 & 6.3 & 38.0 & 0.30 \\
\hline POL & 6.0 & 12894 & 75.7 & 8.3 & 35.0 & 0.91 \\
\hline PRT & 5.3 & 17202 & 78.7 & 10.0 & 42.2 & 1.41 \\
\hline RUS & 5.2 & 11618 & 68.6 & 8.5 & 40.0 & na \\
\hline SVK & 5.9 & 13653 & 74.9 & 12.1 & 37.4 & 1.97 \\
\hline SVN & 5.8 & 17980 & 79.0 & 6.0 & 45.1 & 2.50 \\
\hline SWE & 7.3 & 23450 & 81.4 & 8.5 & 52.3 & 0.51 \\
\hline USA & 7.2 & 33746 & 78.1 & 9.4 & 31.0 & 0.38 \\
\hline Average & 6.6 & 20520 & 79.0 & 8.0 & 45.2 & 0.94 \\
\hline
\end{tabular}

As shown on Figure 1 (Panel A), there is a large cross-country correlation of 0.69 between average life satisfaction and average household disposable income. Over the 2005-2010, there also appears to be a significant correlation, albeit weaker, of 0.26 between the annual change in average life satisfaction and annual disposable income growth (Panel B). This finding is consistent with the view that life satisfaction and income are less correlated with each other in the time dimension than in the cross-section (Easterlin, 1974), although many countries do exhibit significant correlations between growth in life satisfaction and in income even over relatively long periods (Stevenson and Wolfers, 2013). 
Figure 1. -Average Life SATisfation And Household Disposable Income Across

COUNTRIES AND TIME
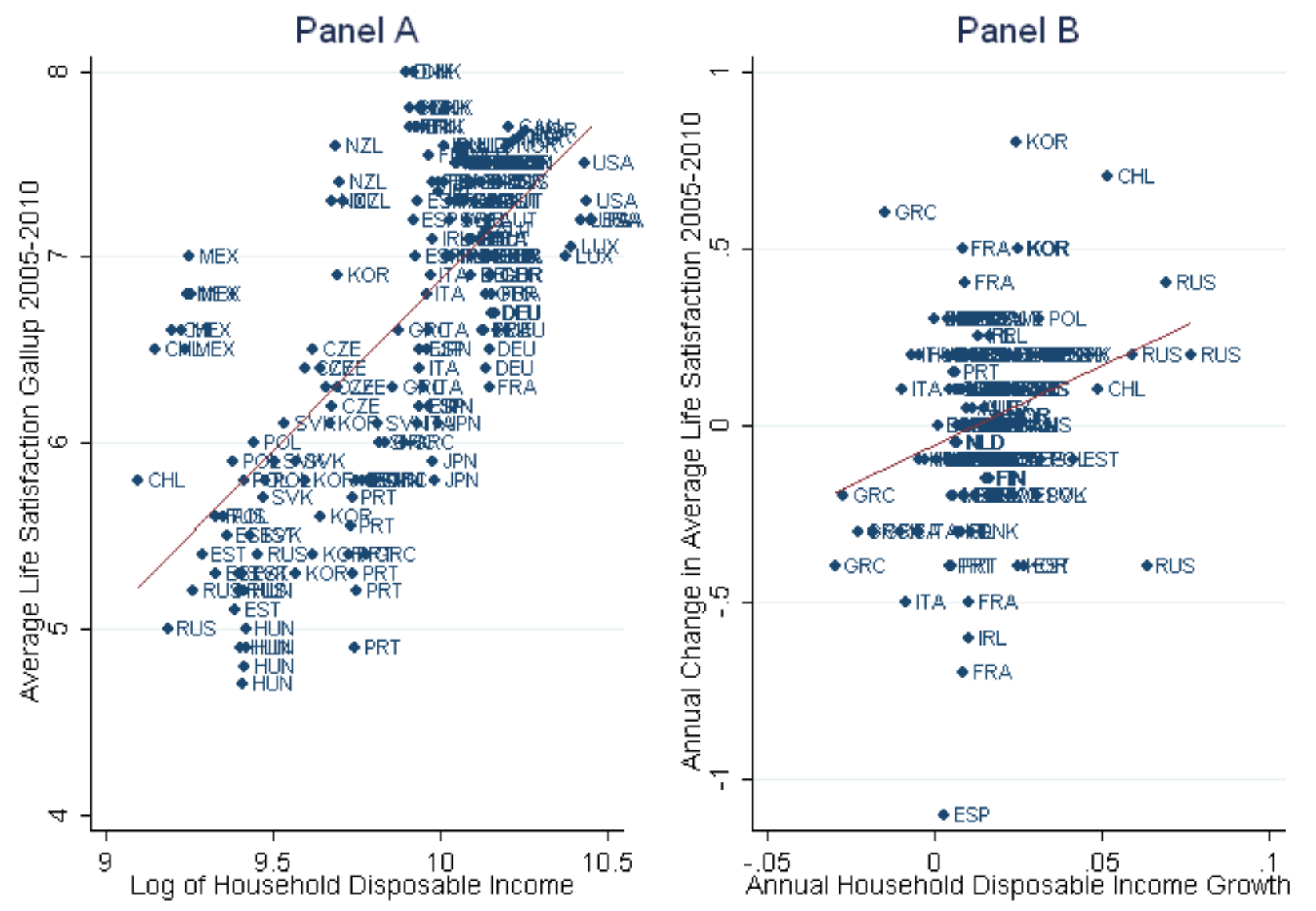

\section{B. Unemployment Variables}

The stock of unemployment $U N$ is extracted from OECD database (OECD, 2013c), while unemployment turnover variables are constructed from a collection of sources (Murtin and Robin, 2013, Murtin et al., 2013, OECD, 2010). Two series can conveniently describe unemployment turnover in a two-state (employment and unemployment) model: the monthly unemployment inflow rate $s$ that captures job destruction, and the monthly unemployment outflow rate $f$ that is driven by both job vacancy creation and the efficiency of the matching process between employers and employees. These two series provide an adequate description of unemployment dynamics, as there is 
a very high correlation between the actual rate of unemployment and the steady-state unemployment rate.

The outflow series $f$ is less noisy than the inflow series (as it is of larger magnitude and hence relatively less sensitive to business cycle fluctuations), which is recalculated implicitly from the unemployment rate and its outflow, so that the following equation holds by construction:

$$
U N=\frac{s}{s+f}
$$

The average duration of the unemployment spell can be easily calculated (in years) from the outflow rate, as it equals $D=1 /(12 f)$. Unemployment spells are particularly short in some Englishspeaking countries such as the Australia, Canada and the United States, and particularly long in Southern and Eastern European countries.

The replacement rate of unemployment benefits has a large influence on the valuation of the unemployment risk, and must therefore be constructed in a very careful way. When workers are laidoff and fall into unemployment, they receive unemployment benefits if they are covered by unemployment insurance (UI). According to ILO (2009), only a fraction of unemployed workers are covered by such a scheme as shown on Table 1. This proportion is larger among high-income countries, but with the exception of Germany, OECD countries are far from providing full coverage.

When the unemployed is covered by UI, she/he receives benefits at a rate $\tau^{c}$ that is proxied by the average of four replacement rates corresponding to a single person with average wage, a person living in a household with one wage-earner, with two wage earners, and to a lone parent. Moreover, these four replacement rates decrease with time and eventually fall quickly to zero for some categories of workers, as it is the case for instance in Italy. To account for this fact, we calculate $\tau^{c}$ as the weighted average of the initial and long-term replacement rates, with a weight equal to unemployment spell's average duration and a maximum spell of 5 years. More precisely, one has: 


$$
\tau^{c}=\frac{5-D}{5} \bar{\tau}^{i, c}+\frac{D}{5} \bar{\tau}^{l t, c}
$$

where $\bar{\tau}^{i, c}$ is the average initial replacement rate calculated across the four groups, and $\bar{\tau}^{l t, c}$ its longterm counterpart. All these rates are extracted from OECD (2013c).

When the unemployed is not covered by UI, we assume that she/he receives income transfers from family, which equal the income earned by the bottom decile of the income distribution as measured by OECD (2013c). Typically, the latter income equals $15 \%$ of the average income in high-inequality emerging countries such as Russia or Mexico, and between $20 \%$ and $40 \%$ of the average income among developed economies. The implicit replacement rate arising from those transfers to non-covered unemployed workers is denoted $\tau^{n c}$. In the data, it is of course never larger than the replacement rate of covered unemployed workers, but among some high-income countries providing small benefits, such as the United States or the United Kingdom, the discrepancy between the two rates is not very large.

As a result, our measure of the effective replacement rate $\tau$ is simply the weighted average of the two latter rates, with a weight equal to the degree of coverage $c$ of UI:

$$
\tau=c \tau^{c}+(1-c) \tau^{n c}
$$

Table 1 shows that the effective replacement rate is on average equal to $45.2 \%$, and ranges between $13.4 \%$ in Mexico and $67.1 \%$ in Germany. Interestingly, unemployment and turnover rates are not very different across these two countries. This suggests that similar unemployment rates and turnover may hide very different income risks across OECD countries, depending on the magnitude of the effective replacement rate.

\section{Subjective Valuation of Vital and Unemployment Risks}

Subjective well-being data are increasingly used to study people's preferences (OECD, 2013a; UK Green Book). Underlying these approaches is the recognition that what matters for a 
good life is the impact of a specific set of circumstances (individual and countrywide) on how people feel about their life, as well as the view that people are the best judges of how their life is going. Because of this, questions on life satisfaction are often used to evaluate how people trade-off different aspects of their life (e.g. work versus leisure) and to express these trade-offs in monetary terms, with the implicit assumption that life satisfaction is a good proxy of individual's utility. This assumption is corroborated by the empirical literature in this field that shows that life satisfaction reflects a cognitive assessment of one's own life and is indeed found to capture decisional utility, (Kahneman et al., 1991; Heliwell and Barrington-Leigh, 2010) as opposed to experienced utility (Kahneman and Krueger, 2006).

Subjective well-being measures are not only theoretically relevant but also relatively easier and cheaper to collect than, for instance, measures elicited through stated-preferences or contingent evaluation methods (OECD, 2013a). Differently from the latter, life satisfaction measures also have the immense advantage of being available on a comparable basis for a large number of countries, a real asset for our research.

This section first describes life satisfaction regressions conducted at the individual level, and then at the country level. Life satisfaction is regressed on (log) income, unemployment and longevity, and the shadow prices of the two latter variables is calculated from their life satisfaction elasticity relative to the life satisfaction elasticity of income.

\section{A. $\quad$ Econometric Issues in Micro-Level Life Satisfaction Regressions}

Economic studies relying on micro-level life satisfaction data often select self-assessed health as a proxy for health. This morbidity-related variable is therefore disconnected from the mortality risk that is considered in this paper. Similarly, unemployment is often included inside life satisfaction micro-level regressions as a dummy taking value one for the currently unemployed and zero otherwise. This variable captures the ex-post effect of unemployment upon the life satisfaction 
of a specific fraction of the population, namely the unemployed, while employed workers are by construction not subject to any welfare loss. We aim to complement the pure ex-post perspective by also valuing the ex-ante unemployment risk, which affects all workers, employed and unemployed ones (although not in an identical ways, as seen below). This paper therefore departs from the two proxies (morbidity and materialized unemployment) commonly used in microeconomic studies. However, there exist economic studies running micro-level life satisfaction regressions with aggregate indicators such as the country unemployment rate (e.g. Boarini et al., 2012) or life expectancy (Deaton, 2008). Those regressions are typically of the form:

$$
L S_{i, j, t}=a_{j}+b_{t}+\gamma X_{i, j, t}+\alpha \log y_{i, j, t}+\beta^{T} T_{j, t}+\beta^{U} U N_{j, t}+\varepsilon_{i, j, t},
$$

where $L S_{i, j, t}$ stands for life satisfaction of individual $i$ in country $j$ at time $t, X_{i, j, t}$ for personal characteristics, $y_{i, j, t}$ for individual (household) income, $T_{j, t}$ for country-level life expectancy ${ }^{5}, U N_{j, t}$ for the rate of unemployment and $\varepsilon_{i, j, t}$ for a residual. From the above regression, the "subjective" compensating income $\delta_{i, j, t}^{S}$ corresponding to one additional year of life satisfaction or one additional percentage point of unemployment is given by:

$$
\delta_{i, j, t}^{s}=y_{i, j, t}\left[1-\exp \left(-\frac{\beta^{k}}{\alpha}\right)\right] \text { with } k \in\{T, U\} .
$$

In this framework, compensating differentials are a share of personal income that is common to all individuals and countries (see Decancq et al., 2015, for a model specification where elasticities $\left(\alpha, \beta^{k}\right)$ depend also on individual characteristics).

Taking stock of the Gallup survey, we estimate the life satisfaction regression above on the sample described in section II and over the 2005-2010 period. We consider both equivalized and total household income, and include several individual controls such as a dummy for females and a quartic in age to account for non-monotonic variation in life satisfaction with age (Wunder et al.,

Life expectancy and the rate of unemployment are taken from the World Development Indicators database (World Bank, 2013). 
2013). In addition, we include country-level life expectancy (lagged one year ${ }^{6}$ ) and the unemployment rate. Time dummies are always included while countries effects are introduced in most of the regressions (columns 3 to 6). Sampling weights have been tested and do not yield plausible results as they drive the shadow prices of health and unemployment at unconventionally high levels.

Table 2 describes the results. Log income is always highly significant, so as the unemployment rate and life expectancy (except on column 4). The elasticity of log income varies little across the various specifications.

As reported at the bottom of Table 2, we derive the compensating differential (as a share of income) corresponding to one additional year of life expectancy and minus one percentage point of unemployment. These "subjective shadow prices" are very large as compared with the model-based prices, with an average of $9 \%$ of income per percentage point of unemployment, and around $11 \%$ per year of life expectancy (ignoring the non-significant estimate in column 4). Given that the average unemployment rate in the sample is $7.1 \%$, this suggests that households would be willing to give up as much as half of their income to eliminate the risk of unemployment. Moreover, these results imply that American households would be willing to give up about $40 \%$ of their total income to reach the same level of life expectancy as in Japan.

On columns 5 and 6, we decompose the shadow price of unemployment by interacting the country-level unemployment rate with an individual-level dummy taking value one if the worker is currently employed.

6 Assuming that progress in life expectancy are observed with a one-year delay. 
TABLE 2. -Micro-LEVEL LifE SATISFACTION REgRESSIONS - 32 COUNTRIES 2005-2010

\begin{tabular}{|c|c|c|c|c|c|c|}
\hline & \multicolumn{2}{|c|}{ No country effects } & \multicolumn{2}{|c|}{ With country effects } & \multicolumn{2}{|c|}{$\begin{array}{c}\text { With country effects } \\
\text { and interactions }\end{array}$} \\
\hline & $\begin{array}{l}\text { OLS } \\
(1)\end{array}$ & $\begin{array}{l}\text { OLS } \\
(2) \\
\end{array}$ & $\begin{array}{l}\text { OLS } \\
(3)\end{array}$ & $\begin{array}{l}\text { OLS } \\
(4)\end{array}$ & $\begin{array}{l}\text { OLS } \\
(5)\end{array}$ & $\begin{array}{l}\text { OLS } \\
(6) \\
\end{array}$ \\
\hline & \multicolumn{6}{|c|}{ Dependent variable is individual life satisfaction } \\
\hline Log of total household income & $\begin{array}{l}0.619^{* * *} \\
(0.007)\end{array}$ & & $\begin{array}{c}0.553^{\star * \star} \\
(0.007)\end{array}$ & & $\begin{array}{c}0.524^{\star * *} \\
(0.007)\end{array}$ & $\begin{array}{l}0.524^{\star * *} \\
(0.007)\end{array}$ \\
\hline Log of household equivalised income & & $\begin{array}{c}0.551^{* * *} \\
(0.007)\end{array}$ & & $\begin{array}{c}0.480^{* * *} \\
(0.007)\end{array}$ & & \\
\hline Unemployment rate & $\begin{array}{c}-0.038^{* * *} \\
(0.002)\end{array}$ & $\begin{array}{c}-0.037^{* * *} \\
(0.002)\end{array}$ & $\begin{array}{c}-0.055^{\star \star *} \\
(0.004)\end{array}$ & $\begin{array}{c}-0.062^{\star * \star} \\
(0.005)\end{array}$ & $\begin{array}{c}-0.055^{\star * *} \\
(0.005)\end{array}$ & \\
\hline Not employed & & & & & $\begin{array}{c}-0.267^{\star \star *} \\
(0.013)\end{array}$ & $\begin{array}{l}-0.050^{*} \\
(0.030)\end{array}$ \\
\hline Unemployment rate $\mathrm{x}$ not employed & & & & & & $\begin{array}{l}-0.071^{* * *} \\
(0.005)\end{array}$ \\
\hline Unemployment rate $\mathrm{x}$ employed & & & & & & $\begin{array}{c}-0.041^{* * *} \\
(0.005)\end{array}$ \\
\hline Lagged life expectancy & $\begin{array}{l}0.071^{\star * *} \\
(0.002)\end{array}$ & $\begin{array}{l}0.071^{\star * *} \\
(0.002)\end{array}$ & $\begin{array}{l}0.079^{\star * *} \\
(0.022)\end{array}$ & $\begin{array}{l}-0.020 \\
(0.030)\end{array}$ & $\begin{array}{l}0.053^{\star *} \\
(0.023)\end{array}$ & $\begin{array}{l}0.054^{\star *} \\
(0.023)\end{array}$ \\
\hline Female dummy & $\begin{array}{l}0.153^{\star \star \star} \\
(0.011)\end{array}$ & $\begin{array}{c}0.152^{* \star *} \\
(0.012)\end{array}$ & $\begin{array}{l}0.136^{\star * *} \\
(0.011)\end{array}$ & $\begin{array}{l}0.132^{* * *} \\
(0.011)\end{array}$ & $\begin{array}{l}0.165^{\star \star *} \\
(0.011)\end{array}$ & $\begin{array}{l}0.165^{\star \star *} \\
(0.011)\end{array}$ \\
\hline Age & $\begin{array}{c}-11.161^{* \star *} \\
(1.693)\end{array}$ & $\begin{array}{c}-17.322^{* * *} \\
(1.790)\end{array}$ & $\begin{array}{c}-5.896^{\star \star \star} \\
(1.628)\end{array}$ & $\begin{array}{c}-10.714^{* * *} \\
(1.721)\end{array}$ & $\begin{array}{c}-7.638^{* * *} \\
(1.667)\end{array}$ & $\begin{array}{c}-7.842^{\star \star \star} \\
(1.666)\end{array}$ \\
\hline $\mathrm{Age}^{2}$ & $\begin{array}{l}21.579^{* * *} \\
(5.656)\end{array}$ & $\begin{array}{c}43.672^{* * *} \\
(5.984)\end{array}$ & $\begin{array}{c}3.062 \\
(5.439)\end{array}$ & $\begin{array}{c}20.670^{* * *} \\
(5.751)\end{array}$ & $\begin{array}{c}3.319 \\
(5.553)\end{array}$ & $\begin{array}{c}3.977 \\
(5.552)\end{array}$ \\
\hline $\mathrm{Age}^{3}$ & $\begin{array}{l}-17.735^{\star *} \\
(7.799)\end{array}$ & $\begin{array}{c}-50.484^{* * *} \\
(8.249)\end{array}$ & $\begin{array}{c}8.430 \\
(7.499)\end{array}$ & $\begin{array}{l}-18.190^{* *} \\
(7.926)\end{array}$ & $\begin{array}{l}14.405^{*} \\
(7.652)\end{array}$ & $\begin{array}{l}13.558^{*} \\
(7.650)\end{array}$ \\
\hline $\mathrm{Age}^{4}$ & $\begin{array}{l}5.499 \\
(3.797)\end{array}$ & $\begin{array}{l}21.760^{\star * *} \\
(4.014)\end{array}$ & $\begin{array}{l}-7.421^{* *} \\
(3.650)\end{array}$ & $\begin{array}{c}5.961 \\
(3.856)\end{array}$ & $\begin{array}{l}-12.331^{\star * *} \\
(3.726)\end{array}$ & $\begin{array}{l}-11.961^{* * *} \\
(3.725)\end{array}$ \\
\hline $\begin{array}{l}\text { Subjective price of one unemployment } \\
\text { percentage point (\% income): average } \\
\text { for the unemployed } \\
\text { for the employed }\end{array}$ & 6.0 & 6.5 & 9.5 & 12.1 & 10.0 & $\begin{array}{l}7.9 \\
12.7 \\
7.5\end{array}$ \\
\hline $\begin{array}{l}\text { Subjective price of not being employed } \\
\text { (\% income) }\end{array}$ & & & & & 40.0 & 9.1 \\
\hline $\begin{array}{l}\text { Subjective price of one year of life } \\
\text { expectancy (\% income) }\end{array}$ & 10.8 & 12.1 & 13.3 & -0.04 & 9.6 & 9.8 \\
\hline Time dummies & Yes & Yes & Yes & Yes & Yes & Yes \\
\hline Country dummies & No & No & Yes & Yes & Yes & Yes \\
\hline $\mathrm{R}^{2}$ & 0.15 & 0.13 & 0.22 & 0.2 & 0.21 & 0.22 \\
\hline $\mathrm{N}$ & $1.2 e+05$ & $1.1 e+05$ & $1.2 e+05$ & $1.1 e+05$ & $1.1 e+05$ & $1.1 e+05$ \\
\hline
\end{tabular}


We also include an individual no-employment dummy to capture the direct "ex-post" cost of non-employment. The latter is found to be very large on column 5 as in other studies, but it is much smaller on column 6 when the interacted unemployment rate (that tests the fact that unemployed people are unhappier the larger is the country-level unemployment rate) is included. Interestingly, the aggregate unemployment rate has indeed a larger negative association with life satisfaction of the non-employed than with life satisfaction of employed workers (i.e. the coefficients are -0.071 and -0.041 respectively). But as before, we find implausibly large shadow prices for both unemployment and health.

Among the various empirical problems contaminating life satisfaction regressions, those affecting the individual income variable are of major importance as they directly affect the magnitude of compensating differentials through the income elasticity $\alpha$. In particular, Powdthavee (2010) highlights the role of large measurement errors on income and of unobserved heterogeneity, which yield a sizeable attenuation bias on income. ${ }^{7}$ He finds an effect of income on life satisfaction twice as large as the estimate in his basic specification.

Similarly, Fujiwara (2013) argues that the "wellbeing valuation" provides biased estimates of the value of non-market goods unless the income variable is instrumented. Strikingly, he finds in his case-study that the coefficient on log income jumps from 0.16 (non-instrumented income variable) to 1.10 (instrumented variable).

In absence of any relevant instrument for individual income and any panel data covering all 32 countries, one can reduce the influence of measurement errors and unobserved heterogeneity by averaging out the data by country, namely by running macro-level regressions of country average life satisfaction on national log household disposable income, life expectancy, the unemployment rate,

Powdthavee underlines the role of omitted factors such as working hours and relatives' income, which are positively related to personal income and negatively linked with life satisfaction. 
country and time dummies. In this way, any measurement error affecting individual variables is presumably washed away, so as unobserved heterogeneity affecting the level of life satisfaction. ${ }^{8}$

We also examine to which extent business cycle shocks affect the shadow prices of mortality and unemployment, as life satisfaction, disposable income and unemployment are plausibly subject to cyclical effects. Business cycle shocks can conveniently be removed by applying a Hoddrick-prescott filter with smooting parameter 50 to the latter variables.

Table 3 reports the results. Across all specifications, log income, life expectancy and unemployment turn out to be significant. Most importantly, the coefficient on income appears to be larger than in micro-level regressions, about twice larger on columns (1, 2, 4 and 5), and five to seven times larger on column (3 and 6). We interpret this finding as the sign that measurement errors and unobserved factors at the individual level have been largely removed by averaging the data at the country level. Moreover, an $\mathrm{R}^{2}$ of 0.99 leaves little room for unobserved variables to bias the estimates.

TABle 3. -MACRO-LEVEl Life SATiSfaCtion Regressions - 32 COUNTRIES 2006-2010

\begin{tabular}{|c|c|c|c|c|c|c|}
\hline & \multicolumn{3}{|c|}{ Actual series } & \multicolumn{3}{|c|}{ Smoothed series } \\
\hline & $(1)$ & (2) & (3) & $(4)$ & $(5)$ & (6) \\
\hline & \multicolumn{6}{|c|}{ Dependent variable is average life satisfaction } \\
\hline Log household disposable income & $\begin{array}{l}1.286^{\star \star \star} \\
(0.213)\end{array}$ & $\begin{array}{l}1.286^{\star * *} \\
(0.216)\end{array}$ & $\begin{array}{c}3.538^{\star \star *} \\
(0.933)\end{array}$ & $\begin{array}{l}1.290^{\star * *} \\
(0.202)\end{array}$ & $\begin{array}{l}1.291^{* * *} \\
(0.205)\end{array}$ & $\begin{array}{c}2.465^{\star \star \star} \\
(0.355)\end{array}$ \\
\hline Unemployment rate & $\begin{array}{c}-0.067^{\star \star \star} \\
(0.014)\end{array}$ & $\begin{array}{c}-0.068^{\star * *} \\
(0.015)\end{array}$ & $\begin{array}{c}-0.063^{\star * *} \\
(0.012)\end{array}$ & $\begin{array}{c}-0.067^{\star \star *} \\
(0.014)\end{array}$ & $\begin{array}{c}-0.066^{\star \star \star} \\
(0.015)\end{array}$ & $\begin{array}{c}-0.041^{\star * *} \\
(0.008)\end{array}$ \\
\hline Lagged life expectancy & $\begin{array}{c}0.058^{\star \star *} \\
(0.022)\end{array}$ & $\begin{array}{l}0.058^{\star \star} \\
(0.023)\end{array}$ & $\begin{array}{l}0.192^{\star *} \\
(0.087)\end{array}$ & $\begin{array}{c}0.059^{\star * *} \\
(0.021)\end{array}$ & $\begin{array}{l}0.060^{\star \star *} \\
(0.022)\end{array}$ & $\begin{array}{c}0.200^{\star * *} \\
(0.036)\end{array}$ \\
\hline $\begin{array}{l}\text { Subjective price of one unemployment percentage point } \\
\text { (\% income) }\end{array}$ & 5.1 & 5.2 & 1.8 & 5.1 & 5.0 & 1.6 \\
\hline $\begin{array}{l}\text { Subjective price of one year of life expectancy } \\
\text { (\% income) }\end{array}$ & 4.4 & 4.4 & 5.3 & 4.5 & 4.5 & 7.8 \\
\hline Time dummies & No & Yes & Yes & No & Yes & Yes \\
\hline Country dummies & No & No & Yes & No & No & Yes \\
\hline $\mathrm{R}^{2}$ & 0.51 & 0.52 & 0.96 & 0.59 & 0.59 & 0.99 \\
\hline $\mathrm{N}$ & 144 & 144 & 144 & 144 & 144 & 144 \\
\hline
\end{tabular}

8 However, this procedure is unable to adequately treat the unobserved heterogeneity affecting the coefficient on log income, which could only be accounted for in a panel data model with random coefficients ("Generalized Latent Mixed Models"). 
As a consequence, the shadow subjective prices of one additional year of life expectancy and of a cut in the unemployment rate by one percentage point appear to be much lower than those described in Table 2. The subjective price of one year of longevity appears to be in the vicinity of $5 \%$ of disposable income, with a range comprised between $4.4 \%$ and $7.8 \%$. The subjective price of a cut by one percentage point of unemployment is worth about $4 \%$ of disposable income and ranges from $1.6 \%$ to $5.2 \%$.

Importantly, the valuation of one year of life expectancy at $5 \%$ of income is in line with traditional estimates of the Value of one Statistical Life-Year (VSLY), as shown by the following back-of-the-envelope calculation. In Murphy-Topel (2006), the VSLY is displayed by age (see Figure 2), and it turns out that the average VSLY, weighted by cohort size in the United States 2005, would equal 213,000 US dollars. This is the amount that each cohort is willing to pay once in a lifetime to gain one year of life. As the average size of a cohort is equal to $0.9 \%$ of total population, the amount to be paid by each individual every year is equal to $0.09 \times 213,000=1,942$ US dollars, or $5.8 \%$ of household disposable income. It is striking that two completely different methods, one based on stated preferences (i.e. life satisfaction) the other one on revealed preferences (i.e. VSL studies) yield almost the same valuation of life.

\section{B. Accounting for Unemployment Benefits}

In the former two tables, the unemployment rate was used as a pure measure of risk given that the average household disposable income already reflects foregone earnings of the unemployed. In reality, unemployed workers receive unemployment benefits at a given replacement rate and for a given duration, which mitigates monetary losses from being laid-off and hence the magnitude of the unemployment risk. To account for the effect of unemployment benefits on life satisfaction, it is convenient as a starting point to include the effective replacement rate inside the regressions. 
As shown in Table 4, the replacement rate is neither significant in level (column 2) nor in interaction with unemployment (column 3). One possible interpretation for this lack of significance is that the replacement rate captures mainly the monetary effect of unemployment, which is already reflected in disposable income, and constitutes as such a poor measure of risk. Said differently, the unemployment risk does not appear to be adequately proxied by an index of the unemployment rate, the replacement rate and their interaction. Let us try to define a proper measure of unemployment risk that reflects both the exposure to the shock (the unemployment rate) and the mitigating influence of the safety net (the replacement rate). Convenient risk measures can be derived theoretically from the specification of individual preferences and their link to life satisfaction. Let us consider the following model,

$$
u(y, U N, T)=E(\tilde{y})(1+\lambda C V(\tilde{y})) \exp (\gamma T) \text { with } \lambda<0
$$

and with $L S=a+\alpha \log (u(y, U N, T))+\varepsilon$ where utility $u($.$) depends positively on the expected$ value of disposable income $\tilde{y}$, negatively on its coefficient of variation, and positively on "healthrelated human capital" defined in an exponential way. ${ }^{9}$ Life satisfaction is then assumed to be a loglinear transformation of utility in order to reflect the link between life satisfaction and log income. Let $y=E(\tilde{y})$. In the Appendix we show that the latter assumptions jointly imply the following specifications for life satisfaction regressions:

$$
\begin{gathered}
L S=a+\alpha \log (y)+\beta^{R} R(U N, \tau)+\beta^{T} T+\varepsilon, \\
R(U N, \tau)=\frac{(1-\tau)\left(U N-U N^{2}\right)^{1 / 2}}{(1-U N+\tau \cdot U N)}
\end{gathered}
$$

Measure $R(U N, \tau)$ can be viewed with a good degree of approximation as the coefficient of variation in income. Table 4 column (4) report the results. All explanatory variables turn out to be strongly significant. It is then straightforward to calculate the compensating differential for one

This is justified by the linear relationship between log income (i.e. monetized human capital) and life expectancy at the cross-country level once some standard of economic development has been reached (i.e. when the Preston curve becomes fully linear). 
additional year of life expectancy and for a cut in one percentage point of unemployment at various replacement rates for both unemployment risk measures. For the unemployment risk, non-linearities of the risk measure imply that the valuation of the risk depends on the level of the unemployment rate. To obtain an average valuation, one calculates the compensating income differential for the elimination of the risk of unemployment and divides the obtained value by the unemployment rate.

Strikingly, the subjective shadow prices of vital and unemployment risks are fully consistent with those derived from a regression with no replacement rate (e.g. column 1). This finding suggests an overall consistency of the wellbeing valuation conducted at the country-level.

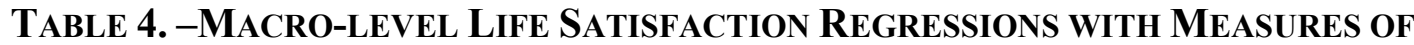 UNEMPLOYMENT RISK}

\begin{tabular}{|c|c|c|c|c|}
\hline & $(1)$ & $(2)$ & (3) & $(4)$ \\
\hline & \multicolumn{4}{|c|}{ Dependent variable is smoothed life satisfaction } \\
\hline $\begin{array}{l}\text { Log household disposable income } \\
\text { smoothed with Hodrick-Prescott filter }\end{array}$ & $\begin{array}{l}2.465^{\star * *} \\
(0.355)\end{array}$ & $\begin{array}{l}1.532^{* * *} \\
(0.439)\end{array}$ & $\begin{array}{l}1.839^{\star \star *} \\
(0.478)\end{array}$ & $\begin{array}{l}1.785^{\star \star \star} \\
(0.487)\end{array}$ \\
\hline $\begin{array}{l}\text { Unemployment rate } \\
\text { smoothed with Hodrick-Prescott filter }\end{array}$ & $\begin{array}{l}-0.041^{* \star *} \\
(0.008)\end{array}$ & $\begin{array}{l}-0.043^{\star \star \star} \\
(0.011)\end{array}$ & $\begin{array}{l}-0.039^{* * *} \\
(0.012)\end{array}$ & \\
\hline Lagged life expectancy & $\begin{array}{c}0.200^{\star \star \star *} \\
(0.036)\end{array}$ & $\begin{array}{c}0.137^{\star \star \star} \\
(0.043)\end{array}$ & $\begin{array}{c}0.120^{* \star *} \\
(0.043)\end{array}$ & $\begin{array}{c}0.143^{\star \star \star} \\
(0.046)\end{array}$ \\
\hline Unemployment effective replacement rate & & $\begin{array}{l}-1.242 \\
(0.981)\end{array}$ & $\begin{array}{l}-0.455 \\
(1.095)\end{array}$ & \\
\hline Unemployment rate $\mathrm{x}$ centered replacement rate & & & $\begin{array}{l}-0.125 \\
(0.080)\end{array}$ & \\
\hline $\begin{array}{l}\text { Unemployment risk measure } \\
\text { coefficient of variation in income }\end{array}$ & & & & $\begin{array}{l}-2.159^{* *} \\
(1.071)\end{array}$ \\
\hline $\begin{array}{l}\text { Subjective price of one unemployment percentage point } \\
\text { (\% income) }\end{array}$ & 1.6 & 2.8 & 2.1 & 2.1 \\
\hline $\begin{array}{l}\text { Subjective price of one year of life expectancy } \\
\text { (\% income) }\end{array}$ & 7.8 & 8.6 & 6.3 & 7.7 \\
\hline Time dummies & Yes & Yes & Yes & Yes \\
\hline Country dummies & Yes & Yes & Yes & Yes \\
\hline $\mathrm{R}^{2}$ & 0.99 & 0.99 & 0.99 & 0.99 \\
\hline $\mathrm{N}$ & 144 & 107 & 107 & 107 \\
\hline
\end{tabular}


As a preliminary conclusion to this section, it is clear that the assessment of vital and unemployment risks can be misleading if the data is not treated appropriately for measurement errors and unobserved heterogeneity, two issues that arise primarily at the micro-economic level, and to a much lower extent at the country-level. We now turn to the discussion of "objective" valuations.

\section{Model-Based Valuations of Vital and Unemployment Risks}

This section presents the model-based approach in two different setups. One is based on a valuation "under the veil of ignorance" which is calculated for an "average" representative worker independently of her current employment state, while the second one corresponds to a statecontingent, individual-level valuation that distinsguishes between two types of workers, namely the employed and the unemployed.

\section{A. Valuation "Under the Veil of Ignorance"}

Expected utility of a representative agent. We consider a hypothetical life-cycle individual facing in each period idyosincratic and uncorrelated vital and unemployment risks, and no aggregate risk. The expected utility of a representative agent making calculations under the "veil of ignorance" regarding consumption $c$ and stochastic longevity prospects $\tilde{T}$ is given by

$$
E\left[\sum_{t=0}^{\tilde{T}} \beta^{t} \tilde{u}(c(t))\right]=E\left[\sum_{t=0}^{\tilde{T}} \beta^{t}\right] E[\tilde{u}(c)]
$$

where $\beta$ is the discount factor and $E[$.$] is the unconditional expectation. { }^{10}$ In this setting, the utility criterion is calculated before the materialization of vital, income and unemployment risks, namely under "the veil of ignorance".

10 The equality follows from Wald's lemma. 
Mortality risk. As Becker et al. (2005) and Jones and Klenow (2011), we consider the benchmark case where the survival rate per period $\pi$ is constant over lifetime, so that life expectancy equals $E(\tilde{T})=T=1 /(1-\pi)$. Expected utility then becomes

$$
\frac{1}{1-\beta \pi} E[\tilde{u}(c)]
$$

Unemployment risk. In the valuation "under the veil of ignorance", we model unemployment in a very simple way, assuming an idiosyncratic risk of unemployment in every yearly period. As the average unemployment spell duration among our sample is 0.94 years (cf. Table 1 in the data section), this assumption is plausible as a starting point. Expected utility can then be rewritten as

$$
\frac{1}{1-\beta \pi}[U N \cdot \tilde{u}(c(u))+(1-U N) \cdot \tilde{u}(c(e))]
$$

where $U N$ is the rate of unemployment, and $c(u)$ and $c(e)$ are consumptions while employed and unemployed. Notice that under the veil of ignorance, and with no aggregate risk, unemployment turnover has no effect on social welfare, which will not be the case with more elaborated models described below. As long as the fraction of employed and unemployed in each period are constant, turnover affects individual but not social welfare. ${ }^{11}$

Indirect utility and calibration. For the purpose of studying mean preserving changes in the unemployment rate, it is convenient to write social welfare in terms of average consumption $y$, and the effective replacement rate $\tau=c(u) / c(e)$. Thus,

$$
y=U N \cdot c(u)+(1-U N) \cdot c(e)=(1-U N+\tau \cdot U N) \cdot c(e)
$$

11 Cordoba and Verdier (2008) also find that social mobility per se does not affect social welfare. 
Assume further that average savings are zero so that $y$ also denotes average income. An indirect utility as a function of average income $y$, the unemployment rate $U N$, and life expectancy $T$ can immediately be derived from above equations:

$$
v(y, U N, \pi)=\frac{1}{1-\beta \pi}\left[U N \cdot \tilde{u}\left(\frac{\tau \cdot y}{1-U N+U N \cdot \tau}\right)+(1-U N) \cdot \tilde{u}\left(\frac{y}{1-U N+U N \cdot \tau}\right)\right] .
$$

To choose the parameters governing the utility function $\tilde{u}($.$) , we calculate the value of a$ statistical life (VSL) implied by the model. The VSL is the society's willingness to pay to save one life, and in practice it will be used to calibrate the intercept of the utility function $\tilde{u}($.$) . It is formally$ calculated as the marginal rate of substitution between income and the survival probability or:

$$
V S L=\left|\frac{\partial v(y, U N, \pi) / \partial \pi}{\partial v(y, U N, \pi) / \partial y}\right| .
$$

Risk valuation, choice of references and equivalent incomes. The derivation of equivalent incomes for the non-income dimensions (longevity and unemployment) hinges on the choice of a reference value for comparison. For both risks, we choose the best possible outcome as a benchmark, namely zero unemployment and the highest longevity $T^{*}$ observed in the sample (Japan). ${ }^{12}$ While longevity never interfers with the calculation of unemployment risk valuation, the converse is not true as unemployment and income are not separable in indirect utility. However, this interaction effect is small empirically, and there is little difference between the valuation of mortality risk at zero and non-zero unemployment. Formally, the compensating income differential for achieving zero unemployment and highest longevity verify respectively

$$
v(y, U N, \pi(T))=v\left(y+\delta^{U}, 0, \pi(T)\right),
$$

12 See Blanchet and Fleurbaey (2013) for a discussion of the choice of the benchmark. It is not necessarily the case that zero unemployment may be an optimal outcome from an economic standpoint, as some degree of frictional unemployment may be useful to enable reallocation of labor and capital in most productive units. But in absence of any information on the "optimal level" of frictional unemployment, we simply consider zero unemployment as the benchmark. 


$$
v(y, U N, \pi(T))=v\left(y+\delta^{T}, U N, \pi\left(T^{*}\right)\right) .
$$

Equivalent incomes admit closed-form expressions for cetain utility functions as shown next.

Becker, Philipson and Soares (2005) augmented for unemployment risk. As a convenient starting point for specifying the utility function, several studies such as Becker et al. (2005), Murphy and Topel (2005) or Hall and Jones (2007) consider a CRRA utility function with intercept

$$
\tilde{u}(c)=\frac{1}{1-\sigma}\left(c^{1-\sigma}-\omega^{1-\sigma}\right)
$$

where $\omega$ is an imputed survival consumption level. It represents a level of consumption that is so low, that individuals would be indifferent between being alive or being dead. After choosing a CRRA utility function with intercept, and inserting it into the measure of indirect utility derived earlier, one obtains:

$$
v(y, U N, \pi)=\frac{1}{(1-\beta \pi)(1-\sigma)}\left[y^{1-\sigma} \frac{1-U N+U N \cdot \tau^{1-\sigma}}{(1-U N+U N \cdot \tau)^{1-\sigma}}-\omega^{1-\sigma}\right]
$$

The VSL and equivalent incomes can easily be derived from the latter equation:

$$
\begin{gathered}
V S L=\frac{-\beta(1-U N+U N \cdot \tau)^{1-\sigma}}{(1-\beta \pi)(1-\sigma)\left(1-U N+U N \cdot \tau^{1-\sigma}\right)} y^{\sigma}\left[y^{1-\sigma} \frac{1-U N+U N \cdot \tau^{1-\sigma}}{(1-U N+U N \cdot \tau)^{1-\sigma}}-\omega^{1-\sigma}\right] \\
\delta^{U}=y\left[\frac{\left(1-U N+U N \cdot \tau^{1-\sigma}\right)^{\frac{1}{1-\sigma}}}{1-U N+U N \cdot \tau}-1\right] \\
\delta^{T}=\left[\frac{1-\beta \pi^{*}}{1-\beta \pi} y^{1-\sigma}+\frac{(1-U N+U N \cdot \tau)^{1-\sigma}}{1-U N+U N \cdot \tau^{1-\sigma}} \beta \frac{\pi^{*}-\pi}{1-\beta \pi} \omega^{1-\sigma}\right]^{\frac{1}{1-\sigma}}-y .
\end{gathered}
$$

These compensating income differentials will be calculated once the utility function $\tilde{u}($.$) has been$ 
calibrated (see later section for a quantitative discussion). Notice that under the veil of ignorance $\delta^{U}$ is a single non-contingent willingness to pay in order to eliminate unemployment. Such willingness to pay may be very different among individuals, some of whom are unemployed. We next consider state-contingent compensations.

\section{B. $\quad$ Tearing the Veil of Ignorance: Contingent, Individual-Level Valuation}

In reality, the valuation of the unemployment risk is not independent from the current employment situation, and the approach under the veil of ignorance fails to account for an important component reflected by subjective data: the welfare loss from the materialization of the unemployment risk for the unemployed. In life satisfaction data, the unemployed report large decreases in life satisfaction due to their current status, which are not reflected in the approach working under the veil of ignorance. In the following, we look more closely at state-contingent, individual-level valuations.

Indirect utility of the employed and the unemployed in the CRRA case. Let $v(s)$ be a shorthand for the value function in state $s$. Consider a recursive formulation where the value function is equal to the utility of the current period plus the discounted expected value at the beginning of next period conditional on current state. Formally, the value function satisfies the following recursion:

$$
\begin{gathered}
v(s)=\tilde{u}(c(s))+\beta \pi E\left[v\left(s^{\prime}\right) \mid s\right] \text { with } s \in\{e, u\}, \\
E\left[v\left(s^{\prime}\right) \mid s\right]=\rho(s) v(e)+(1-\rho(s)) v(u),
\end{gathered}
$$

where $\tilde{u}($.$) is the CRRA utility function with intercept and (\rho(e), \rho(u))$ denote the probability of being employed next period conditionally on being currently employed or unemployed respectively. It is convenient to define $w(s)=\frac{1}{1-\sigma} v(s)^{1-\sigma}$. As shown in the Appendix, the value functions for the currently unemployed and the currently employed are given by: 


$$
\begin{gathered}
w(u)=\frac{1}{1-\beta \pi}\left[\frac{\tilde{u}(c(u))(1-\beta \pi \rho(e))+\beta \pi \rho(u) \tilde{u}(c(e))}{1-\beta \pi(\rho(e)-\rho(u))}\right], \\
w(e)=\frac{1}{1-\beta \pi}\left[\frac{\tilde{u}(c(e))(1-\beta \pi(1-\rho(u)))+\beta \pi(1-\rho(e)) \tilde{u}(c(u))}{1-\beta \pi(\rho(e)-\rho(u))}\right] .
\end{gathered}
$$

Calibration and compensating income differentials. The VSL is calculated for each group of workers, while using current income in the computation of the partial derivative vis-à-vis income, in other words,

$$
\operatorname{VSL}(s)=\left|\frac{\partial w(s) / \partial \pi}{\partial w(s) / \partial c(s)}\right|=\frac{\beta E\left[w\left(s^{\prime}\right) \mid s\right]}{c(s)^{-\sigma}}
$$

Then, an average VSL for the whole population is computed and confronted with relevant empirical evidence (Viscusi and Aldy, 2003) .The average VSL is defined as:

$$
V S L=(1-U N) \operatorname{VSL}(e)+U N \cdot V S L(u)
$$

Although compensating incomes can be derived in closed-form, their expression are complicated and do not yield specific insights. In practice, equivalent incomes are calculated numerically for each workers on each state (employed/unemployed). Specifically, the compensating differential for eliminating unemployment risk for an individual currently in state $s$ solves:

$$
w(c(s), \rho(s) ; \boldsymbol{c}, \boldsymbol{\rho}, \boldsymbol{\pi}(\boldsymbol{T}))=w\left(c(s)+\delta^{U}(s), 1 ; \boldsymbol{c}+\boldsymbol{\delta}^{U}, \mathbf{1}, \boldsymbol{\pi}(\boldsymbol{T})\right)
$$

where $c(s), \rho(s)$ and $\delta^{U}(s)$ are individual-level variables, while aggregate vectors $\boldsymbol{c}+\boldsymbol{\delta}^{\boldsymbol{U}}, \mathbf{1}, \boldsymbol{\pi}(\boldsymbol{T})$ contain entries for both states (employed and unemployed). Notice that the elimination of unemployment risk corresponds to setting $\rho(e)=\rho(u)=1$. In other words, compensating income $\delta^{U}(s)$ is the amount of money that compensates the worker of type $s$ for the absence of unemployment in the calculation of future expected utility. In this setting, the associated gain in utility is larger for the unemployed than for the employed, who currently enjoys higher income. As a consequence, the compensating differential of the unemployed $\delta^{U}(u)$ is larger than the one of the 
employed $\delta^{U}(e)$, which simply captures the unemployment risk premium. Similarly, the compensating differential for achieving the highest longevity $T^{*}$ for an individual currently in state $S$ solves:

$$
w(c(s), \rho(s) ; \boldsymbol{c}, \boldsymbol{\rho}, \boldsymbol{\pi}(\boldsymbol{T}))=w\left(c(s)+\delta^{T}(s), \rho(s) ; \boldsymbol{c}+\boldsymbol{\delta}^{\boldsymbol{T}}, \boldsymbol{\rho}, \boldsymbol{\pi}\left(\boldsymbol{T}^{*}\right)\right) .
$$

Once worker-specific compensating differentials have been derived, it is then possible to calculate an average value as follows:

$$
\begin{aligned}
& \delta^{U}=(1-U N) \cdot \delta^{U}(e)+U N \cdot \delta^{U}(u) \\
& \delta^{T}=(1-U N) \cdot \delta^{T}(e)+U N \cdot \delta^{T}(u)
\end{aligned}
$$

Our calculations show that $\delta^{T}, \delta^{T}(e)$ and $\delta^{T}(u)$ are only marginally different, so that disentangling compensating incomes for the employed and unemployed appears to be important for the unemployment risk but not for the mortality risk.

\section{C. $\quad$ Tearing the Veil of Ignorance in an Epstein-Zin-Weil Utility Framework}

In what follows, we similarly use a recursive utility framework that yields a higher valuation to the elimination of unemployment for the unemployed. However, we use a different representation for individual preferences that allows us to introduce specific risk aversion parameters for the vital and unemployment risks. In practice, we use a generalized Epstein-Zin-Weil utility function, which has several conceptual advantages over the CRRA utility function as we turn to explain.

Three issues with the CRRA utility function. Both valuations "under the veil of ignorance" or at the individual level may be affected by the choice of a CRRA utility function, which presents mainly three issues. First, the CRRA utility function assumes that individuals are indifferent to the timing of resolution of uncertainty. As discussed in Cordoba and Ripoll (2013), this assumption is 
analytically convenient but it carries implications that appear implausible, at least in what concerns health and mortality risks. Evidence suggests that in the case of incurable diseases, individuals are not indifferent to the timing of resolutions of uncertainty, but that they rather prefer late resolution, what is sometimes called "protective ignorance." For example, studies regarding predictive genetic testing for the Huntington's disease find that a sizable portion of the population at risk prefers not to know. Individuals cite as the major reasons to avoid being tested "fear of adverse emotional effects after an unfavorable diagnosis, such as deprivation of hope, life in the role of a patient, obsessive searching for symptoms and inability to support one's spouse" (Yaniv et al., 2004, p. 320). Wexler (1979) describes the results of 35 interviews with individuals at risk for the disease as follows: "All of the interviewers were painfully aware that the disease is terminal, but for them termination comes not at the moment of death but at the moment of diagnosis. Most fantasize the period following diagnosis to be a prolonged and unproductive wait on death row" (p. 199-220). Studies of HIV testing avoidance also find that many individuals exhibit some type of protective ignorance. For example, Day et al. (2003, p. 665) conclude that the major barriers to voluntary counseling and testing were "fear of testing positive for HIV and the potential consequences, particularly stigmatization, disease and death."

Second, the CRRA utility function does not disentangle risk aversion and intertemporal substitution. In the case of mortality, this framework predicts that the marginal utility of survival is constant, a natural consequence of a formulation in which utility is linear in probabilities. This means that a patient in the model values equally a procedure that provides one additional percentage point of survival regardless of whether the chances of survival without the procedure are $5 \%$ or $95 \%$. A CRRA utility function in which the elasticity of intertemporal substitution (EIS) is equal to the inverse of the coefficient of relative risk aversion (RRA) is the standard way of obtaining a representation in which utility is linear in probabilities and individuals are indifferent to the timing of resolution of uncertainty. In contrast, as proposed in Cordoba and Ripoll (2013), an Epstein-Zin-Weil 
utility function disentangles the EIS from the RRA, and yields a representation in which individuals prefer late resolution of mortality uncertainty and in which the marginal utility of survival is decreasing in survival. Specifically, this can be achieved when the EIS is lower than the inverse of the CRRA. As we show later, disentangling the EIS from the RRA is key to partially reconcile the subjective monetary valuations with the model-based valuations obtained from models of health and unemployment.

A third piece of evidence regarding the limitations of the CRRA utility function, at least in regards to health issues, is that it is inconsistent with available evidence regarding the value of statistical life (VSL). The VSL is an estimate of the social willingness to pay to save one life, and it is widely used for policy analysis. For example, in the United States the Environmental Protection Agency employs a VSL of $\$ 6.3$ million for cost-benefit analysis, while the Department of Transportation uses \$5.8 million. Evidence compiled in Viscusi and Aldy (2003) suggests that the VSL-to-income ratio is decreasing in income. In other words, poorer individuals seem to value life relative to their annual income more than richer people do. Contradicting this evidence, the CRRA utility function predicts that the VSL-to-income ratio increases with income. Similarly, the CRRA implies that life could be a bad rather than a good for poor individuals whose consumption is below a certain minimum consumption level (see Cordoba and Ripoll, 2013). ${ }^{13}$

13 Other utility functions drawn from behavioural economics have been considered. First, the well-known Easterlin paradox (Easterlin, 1974, 1995) pointing at the relative stagnation of average happiness despite sharp increases in income is classicaly explained by the presence of relative income terms in the utility function (Clark et al., 2008). Income, whenever received in employment or unemployment, is evaluated relative to others, namely with respect to a given reference income $X$. Many examples of utility functions reflecting inter-dependent preferences (Pollack, 1976), "keeping up with the Joneses" effects (Ljungqvist and Uhlig, 2000), or habits (Caroll et al., 1997, 2000) are exemplified in the economic literature. However, relative evaluation per se is unable to account for the large shadow price of unemployment found in subjective well-being studies. Second, another effect at play, namely loss aversion, has been examined. Indeed, Kahneman et al. (1991) conclude from experiments that individuals are about twice as sensitive to losses as they are to gains. They label loss aversion the observation that the marginal utility of agents is larger in the domain of losses than in the domain of gains. Building on the latter two ideas, we constructed a behavioural utility function with loss aversion below a certain reference threshold, in practice average income, so that the unemployed would displays loss aversion. However, this type of utility function has the unpleasant property of displaying negative values in the income loss domain, implying that some unemployed workers have lower utility than a dead person. This inconsistency arises from the mutually exclusive objectives of setting up a utility function with a low curvature at the reference income (in order to obtain a low imputed consumption if dead) and a high curvature immediately below the average income. 
Utility of the employed and the unemployed in the Epstein-Zin-Weil case. We extend the non-expected utility model of mortality risk $^{14}$ in Cordoba and Ripoll (2013) to also include unemployment risk. The main feature of this extension is the disentangling of three distinct parameters: one that controls intertemporal substitution, one that controls unemployment risk aversion, and one that controls mortality risk aversion.

Continue to denote the employed and unemployed states $s=(e, u)$. Let $v(s)$ be the indirect utility of individual in state $s$, which is given by

$$
v(s)=\left[(c(s))^{1-\sigma}+\beta\left[\pi E\left[v\left(s^{\prime}\right)^{1-\eta} \mid s\right]^{\frac{1-\gamma}{1-\eta}}+(1-\pi) B^{1-\gamma}\right]^{\frac{1-\sigma}{1-\gamma}}\right]^{\frac{1}{1-\sigma}}
$$

where as in Cordoba and Ripoll (2013) $1 / \sigma$ is the EIS, $\gamma$ is the coefficient of risk aversion vis-à-vis mortality risks, and $B$ reflects a benchmark level of utility at which individuals would be indifferent between being alive or dead. In addition,

$$
E\left[v\left(s^{\prime}\right)^{1-\eta} \mid s\right]=\rho(s) v(e)^{1-\eta}+(1-\rho(s)) v(u)^{1-\eta},
$$

where $\rho(s)$ is the conditional probability of being employed given status $s$ in the previous period, while $\eta$ is the coefficient of "unemployment risk aversion." When the bechnamark value is normalized to zero $(B=0)$, which requires $\gamma \in(0,1)$, then we have

$$
v(s)=\left[(c(s))^{1-\sigma}+\tilde{\beta}(\pi) E\left[v\left(s^{\prime}\right)^{1-\eta} \mid s\right]^{\frac{1-\sigma}{1-\eta}}\right]^{\frac{1}{1-\sigma}},
$$

where $\tilde{\beta}(\pi) \equiv \pi^{\frac{1-\sigma}{1-\gamma}}$ can be interpreted as the "effective discount factor." Given the facts that $\pi<1$ and most calibrations of $\sigma$ indicate that $\sigma>1$, restriction $\gamma \in(0,1)$ implies that $\tilde{\beta}(\pi)>\beta$, so that individuals under this non-expected utility model are intrinsically more patient. This captures the

14 Non-expected utility models depart from the classical expected utility framework that displays some refutable implications pinpointed by several authors, including Maurice Allais and more recently Daniel Kahneman and Amos Tversky. It turns out that empirically speaking, a majority of subjects express preferences that are inconsistent with expected utility. 
preference for late resolution of death uncertainty documented above, which in general holds when $\sigma>\gamma$

The standard expected utility model can be obtained as a special case when $\sigma=\gamma=\eta$. The advantage of this specification is twofold. First, since it can accommodate the case $\sigma>\gamma$, then the model is consistent with a decreasing marginal utility of survival and with a preference for late resolution of death uncertainty. Second, since it can accommodate the case $>\sigma$, it is in principle possible to generate larger model-based valuations of eliminating unemployment risk, because the larger the $\eta$, the larger the aversion to unemployment risk.

Calibration and compensating income differentials. A formula to compute the VSL can be derived from the model above. The formula is key for the calibration of the model, as it allows us to identify the value of the coefficient of mortality risk aversion $\gamma$. The VSL corresponds to the marginal rate of substitution between income and survival. In this non-expected utility model the VSL for state $s$ is given by

$$
V S L(s)=\frac{\tilde{\beta}^{\prime}(\pi) E\left[v\left(s^{\prime}\right)^{1-\eta} \mid s\right]^{\frac{1-\sigma}{1-\eta}}}{(1-\sigma) c(s)^{-\sigma}}
$$

For given state $s$, the VSL corresponds to the change in the weight that the individual gives to the future as proxied by the derivative $\tilde{\beta}^{\prime}(\pi)$, times the future expected lifetime utility $E\left[v\left(s^{\prime}\right)^{1-\eta} \mid s\right]^{\frac{1-\sigma}{1-\eta}}$ where $s^{\prime}$ is the unknown future state, divided by the marginal utility of consumption (income) $(1-\sigma) c(s)^{-\sigma}$. As before, we aggregate across states by using the fraction of unemployed $U N$ as computed above. In other words,

$$
V S L=(1-U N) \cdot V S L(e)+U N \cdot V S L(u) .
$$

Then, we can compute a state-dependent willingness to pay, which takes more the perspective of the individual, either as currently employed or unemployed. In this case, the health premium $\delta^{T}(s)$ of an 
individual in state $s$, who consumes $y(s)$ and lives in a country with survival probability $\pi$ and replacement rate $\tau$ is given by

$$
v(c(s), \rho(s) ; \boldsymbol{c}, \boldsymbol{\rho}, \boldsymbol{\pi}(\boldsymbol{T}))=v\left(c(s)+\delta^{T}(s), \rho(s) ; \boldsymbol{c}+\boldsymbol{\delta}^{\boldsymbol{T}}, \boldsymbol{\rho}, \boldsymbol{\pi}\left(\boldsymbol{T}^{*}\right)\right),
$$

while the unemployment premium $\delta^{U}(s)$ for an individual in state $s$ solves

$$
v(c(s), \rho(s) ; \boldsymbol{c}, \boldsymbol{\rho}, \boldsymbol{\pi}(\boldsymbol{T}))=w\left(c(s)+\delta^{U}(s), 1 ; \boldsymbol{c}+\boldsymbol{\delta}^{\boldsymbol{U}}, \mathbf{1}, \boldsymbol{\pi}(\boldsymbol{T})\right) .
$$

Under this perspective, the aggregate compensating income differentials are given by

$$
\delta^{k}=(1-U N) \cdot \delta^{k}(e)+U N \cdot \delta^{k}(u) \text { with } k \in\{T, U\}
$$

The Appendix considers the case in which $\sigma=\eta$, when closed-form solutions can be obtained.

\section{D. $\quad$ Choice of parameters}

CRRA utility function with intercept. Consider again the CRRA utility function with intercept from Becker et al. (2005)

$$
\tilde{u}(c)=\frac{1}{1-\sigma}\left(c^{1-\sigma}-\omega^{1-\sigma}\right)
$$

Under this specification the shadow price of vital risk depends on both the inverse of the EIS $\sigma$ and the imputed subsistence level of consumption $\omega$. In constrat, the shadow price of the unemployment risk depends only on $\sigma$.

Consumption level $\omega$ is calibrated to the VSL as estimated by Viscusi and Aldy (2003). They assess a VSL between 4 and 9 million (2004) USD in the United States, and derive the tighter range of 5.5-7.6 millions USD per statistical life using a meta-analysis. Several studies and costbenefit analysis by government agencies (see Dockins et al., 2004; Murphy and Topel, 2005), including the US Environmental Protection Agency use the average value of 6.3 million USD.

Importantly, the VSL pertains to adult workers and ignores the (unrevealed) VSL of the child. However, surveys based on stated-preferences suggest a significantly larger VSL for the child 
(Hammitt and Haninger, 2010; Alberini et al, 2010). Thus calibrating expected utility over a lifetime on the statistical value of an adult's remaining lifetime is inconsistent.

A simple way of ensuring consistency between the model and the empirical evidence is therefore to use life expectancy at age 20 rather than life expectancy at birth. In practice, we propose a simple adjustment of life expectancy to $T-20$. As life expectancy at age 20 is not available for all countries, this adjustment is more convenient. Moreover, differences in child mortality are not large in our sample of OECD countries.

Table 5 shows the parameters yielding a VSL of 6.3 millions USD in the United States in 2004. For the CRRA utility function with intercept, we find that all subsistence consumption levels are low. In all calculations, parameter $\sigma$ is equal to 1.25 as in Murphy and Topel (2005), which matches a benchmarck EIS of 0.8. ${ }^{15}$

Epstein-Zin-Weil utility function. In the special case in which $\sigma=\eta$, the VSL can be expressed in closed form (see Appendix). In the general case, there is no such formula and the VSL is calculated numerically. As the Epstein-Zin-Weil utility function allows to disentangle risk aversion from the EIS, we fix $\sigma=1.25$ in all calculations.

To calibrate the health-related risk aversion $\gamma$ and its unemployment-related counterpart $\eta$, we calculate the VSL over a grid of those two parameters. The VSL happens to be equal to 6.3 million USD for $\gamma=0.676$ regardless of the value of $\eta$. We therefore select the latter value for $\gamma$. We try different values of unemployment risk aversion parameter $\eta$. We now turn to the comparison of "objective" (model-based) and subjective valuations of the two latter risks.

15 Interestingly, larger values of the $\sigma$ imply a larger shadow price of unemployment, but also a larger imputed consumption if dead $B$ in order to match the VSL. At $\sigma=6$, the value of $B$ that yields a 6.3 million USD is beyond 15,000 USD, a threshold that is larger than the average household income in many countries of our sample. This is why we stick to the value of $\sigma=1.25$ when using the CRRA utility function. 
TABLE 5. -CALIBRATION OF MODELS

\begin{tabular}{|c|c|c|c|c|c|}
\hline & \multicolumn{3}{|c|}{ CRRA } & \multicolumn{2}{|c|}{ Epstein-Zin-Weil } \\
\hline & $\begin{array}{l}\text { Ex-ante with life } \\
\text { expectancy at birth }\end{array}$ & Ex-ante with $T=T-20$ & Recursive with $\mathrm{T}=\mathrm{T}-20$ & $\begin{array}{c}\text { Recursive with } T=T-20 \\
\text { and low unemployment } \\
\text { risk aversion }\end{array}$ & $\begin{array}{c}\text { Recursive with } \mathrm{T}=\mathrm{T}-20 \\
\text { and high unemployment } \\
\text { risk aversion }\end{array}$ \\
\hline $\mathrm{D}$ & 351 & 267 & 284 & 0 & 0 \\
\hline$\sigma$ & 1.25 & 1.25 & 1.25 & 1.25 & 1.25 \\
\hline$\eta$ & - & - & - & 1.25 & 25 \\
\hline $\mathrm{Y}$ & - & - & - & 0.676 & 0.676 \\
\hline Implied VSL (USA 2004) & 6.3 & 6.3 & 6.3 & 6.3 & 6.3 \\
\hline
\end{tabular}

\section{Is There a Law of One Shadow Price?}

A. Is there a law of one shadow price?

Table 6 and Figure 2 report the compensating incomes calculated from the two approaches. For the subjective one, we select shadow prices derived from the inclusion of the unemployment rate into life satisfaction regressions (Table 3 Column 3) or from the inclusion of the income risk measure that aggregates information on both unemployment and the replacement rate (Table 4 Column 4).

As shown on Figure 2, the valuations of health derived from subjective data are larger than the model-based counterpart derived from the simple CRRA framework under the veil of ignorance (third set of bars) by a factor of three. Interestingly, adjusting life expectancy to account for the remaining lifetime of an adult (i.e. using $T-20$ ) helps a lot reconciling model-based and subjective health shadow prices (fourth set of bars). Then, the Epstein-Zin-Weil utility function raises the valuation of health among low-income countries, and hence the average valuation. As a result, the subjective valuation of health as given by the second set of bars is almost equal to the model-based valuation provided by the Epstein-Zin-Weil utility function.

Turning to the valuation of unemployment, the subjective shadow prices appear to be at least four times larger than that derived from the simple CRRA framework under the veil of ignorance. Adopting state-contingent, individual-level valuations with the CRRA utility function 
replicates about half of the subjective valuation as shown by the fifth set of bars. Finally, subjective and model-based shadow prices of unemployment can be matched by setting a (very) large unemployment risk aversion in the Epstein-Zin-Weil utility function. While a RRA coefficient of 25 may seem large relative to the existing evidence on portofolio management and financial risks, the RRA pertaining to the risk of unemployment is, to the best of our knowledge, unexplored territory. As a result, the Epstein-Zin-Weil utility function can also account for the subjective shadow price of unemployment.

Table 6 reveals a few interesting differences across countries. For instance, the Epstein-ZinWeil utility function yields higher compensating differentials for longevity relative to the CRRA case among lower-income countries. For instance, the willingness-to-pay for a longer life is about 50\% larger in Eastern European countries (e.g. CZE, EST) or emerging countries (e.g. MEX) with Epstein-Zin-Weil preferences than with a CRRA utility function (both with adjusted longevity). 


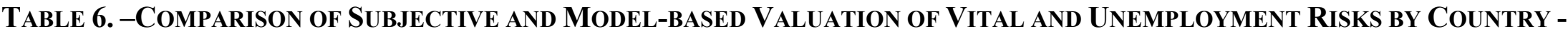
2009

\begin{tabular}{|c|c|c|c|c|c|c|c|c|c|c|c|c|c|c|}
\hline & \multicolumn{2}{|c|}{$\begin{array}{l}\text { SUBJECTIVE Table } 3 \\
\text { column } 3\end{array}$} & \multicolumn{2}{|c|}{$\begin{array}{l}\text { SUBJECTIVE Table } 3 \\
\text { Column } 4\end{array}$} & \multicolumn{2}{|c|}{$\begin{array}{c}\text { CRRA } \\
\text { non-adjusted T w=351 }\end{array}$} & \multicolumn{2}{|c|}{$\begin{array}{c}\text { CRRA } \\
\text { adjusted } T \text { w=276 }\end{array}$} & \multicolumn{2}{|c|}{$\begin{array}{c}\text { CRRA } \\
\text { recursive and adjusted T } \\
\text { W=284 } \\
\end{array}$} & \multicolumn{2}{|c|}{$\begin{array}{c}\text { EPSTEIN-ZIN-WEIL } \\
\text { adjusted T eta }=1.25 \\
\text { gam }=0.676\end{array}$} & \multicolumn{2}{|c|}{$\begin{array}{c}\text { EPSTEIN-ZIN-WEIL } \\
\text { adjusted T eta }=25 \text { gam }=0.676\end{array}$} \\
\hline & $T$ & $U$ & $T$ & $U$ & $T$ & $U$ & $T$ & $U$ & $\mathrm{~T}$ & $\mathbf{U}$ & $\mathrm{T}$ & $U$ & $T$ & $U$ \\
\hline AUS & -1856 & -2470 & -2691 & -3752 & -916 & -568 & -1592 & -568 & -1571 & -1336 & -1581 & -1381 & -1579 & -1700 \\
\hline AUT & -3698 & -2134 & -5268 & -2475 & -1893 & -162 & -3239 & -162 & -3180 & -662 & -3265 & -657 & -3262 & -801 \\
\hline BEL & -3903 & -3239 & -5537 & -3345 & -1968 & -335 & -3361 & -335 & -3310 & -1346 & -3479 & -1286 & -3501 & -1835 \\
\hline CAN & -3054 & -3651 & -4381 & -4305 & -1547 & -667 & -2664 & -667 & -2634 & -1703 & -2661 & -1784 & -2673 & -2035 \\
\hline CHE & -1169 & -1795 & -1706 & -2132 & -569 & -119 & -994 & -119 & -974 & -619 & -982 & -571 & -971 & -835 \\
\hline $\mathrm{CHL}$ & -1912 & -1540 & -2681 & -2575 & -637 & -1349 & -1117 & -1349 & na & na & na & na & na & na \\
\hline CZE & -4307 & -1793 & -5924 & -2109 & -1946 & -243 & -3286 & -243 & -3237 & -881 & -4092 & -844 & -4194 & -1374 \\
\hline DEU & -3956 & -3332 & -5619 & -2709 & -2027 & -169 & -3462 & -169 & -3400 & -964 & -3515 & -899 & -3519 & -1181 \\
\hline DNK & -4251 & -2088 & -5949 & -2049 & -2049 & -148 & -3478 & -148 & -3416 & -602 & -3892 & -611 & -3923 & -704 \\
\hline ESP & -1621 & -5885 & -2350 & -4145 & -743 & -829 & -1297 & -829 & -1289 & -2692 & -1386 & -2708 & -1399 & -3294 \\
\hline EST & -4317 & -2682 & -5794 & -2493 & -1816 & -713 & -3052 & -713 & -3051 & -1782 & -4332 & -1787 & -4618 & -2703 \\
\hline FIN & -3405 & -2953 & -4830 & -2719 & -1631 & -284 & -2795 & -284 & -2751 & -1001 & -3035 & -1026 & -3048 & -1179 \\
\hline FRA & -2448 & -3830 & -3529 & -3715 & -1219 & -417 & -2109 & -417 & -2078 & -1519 & -2111 & -1496 & -2109 & -1929 \\
\hline GBR & -3704 & -3332 & -5275 & -4393 & -1874 & -799 & -3209 & -799 & -3180 & -1960 & -3281 & -1980 & -3325 & -2755 \\
\hline GRC & -2762 & -3140 & -3939 & -4173 & -1262 & -976 & -2178 & -976 & -2172 & -2264 & -2445 & -2280 & -2530 & -4127 \\
\hline HUN & -4616 & -1958 & -6136 & -2113 & -1990 & -358 & -3319 & -358 & -3286 & -1173 & -4712 & -1156 & -5018 & -2192 \\
\hline IRL & -3368 & -4538 & -4795 & -3477 & -1649 & -526 & -2829 & -526 & -2795 & -2034 & -2983 & -1957 & -3013 & -2739 \\
\hline ITA & -1662 & -2707 & -2405 & -3644 & -755 & -713 & -1316 & -713 & -1305 & -1827 & -1425 & -1829 & -1456 & -3635 \\
\hline JPN & 0 & -1933 & 0 & -3392 & 0 & -646 & 0 & -646 & 0 & -1339 & 0 & -1369 & 0 & -1932 \\
\hline KOR & -2022 & -998 & -2888 & -2319 & -836 & -411 & -1454 & -411 & na & na & na & na & na & na \\
\hline LUX & -4631 & -2841 & -6597 & -3369 & -2568 & -237 & -4372 & -237 & -4297 & -973 & -4089 & -946 & -4088 & -1225 \\
\hline MEX & -2934 & -901 & -4008 & -2043 & -1084 & -850 & -1863 & -850 & -1871 & -1220 & -2847 & -1262 & -3165 & -3511 \\
\hline NLD & -2861 & -1518 & -4099 & -2171 & -1405 & -126 & -2422 & -126 & -2375 & -519 & -2497 & -502 & -2488 & -662 \\
\hline NOR & -2997 & -1519 & -4306 & -2404 & -1547 & -141 & -2664 & -141 & -2614 & -501 & -2599 & -508 & -2585 & -604 \\
\hline NZL & -1858 & -1734 & -2667 & -2433 & -783 & -460 & -1364 & -460 & -1348 & -1020 & -1618 & -1056 & -1628 & -1310 \\
\hline POL & -4188 & -1766 & -5673 & -2616 & -1783 & -540 & -3005 & -540 & -2985 & -1222 & -4114 & -1233 & -4317 & -1967 \\
\hline PRT & -3509 & -2811 & -4919 & -3338 & -1570 & -604 & -2684 & -604 & -2662 & -1724 & -3216 & -1705 & -3315 & -2919 \\
\hline RUS & -6279 & -1630 & -7931 & -2041 & -2985 & -391 & -4786 & -391 & na & na & na & na & na & na \\
\hline SVK & -4819 & -2645 & -6473 & -2903 & -2123 & -716 & -3548 & -716 & -3542 & -1869 & -4831 & -1895 & -5215 & -3733 \\
\hline SVN & -3478 & -1824 & -4889 & -2505 & -1584 & -339 & -2709 & -339 & -2671 & -1119 & -3164 & -1132 & -3273 & -3050 \\
\hline SWE & -1927 & -3277 & -2789 & -3423 & -925 & -415 & -1609 & -415 & -1585 & -1308 & -1650 & -1333 & -1646 & -1595 \\
\hline USA & -7797 & -5191 & -10849 & -7080 & -4456 & -1929 & -7416 & -1929 & -7423 & -3775 & -7254 & -3906 & -7505 & -4984 \\
\hline Average & -3291 & -2614 & -4590 & -3074 & -1567 & -537 & -2662 & -537 & -2655 & -1412 & -3002 & -1417 & -3081 & -2156 \\
\hline
\end{tabular}


Figure 2. -AVERAGE COMPENSATING INCOME DifFERENTIALS FOR VITAL AND UNEMPLOYMENT RISKS

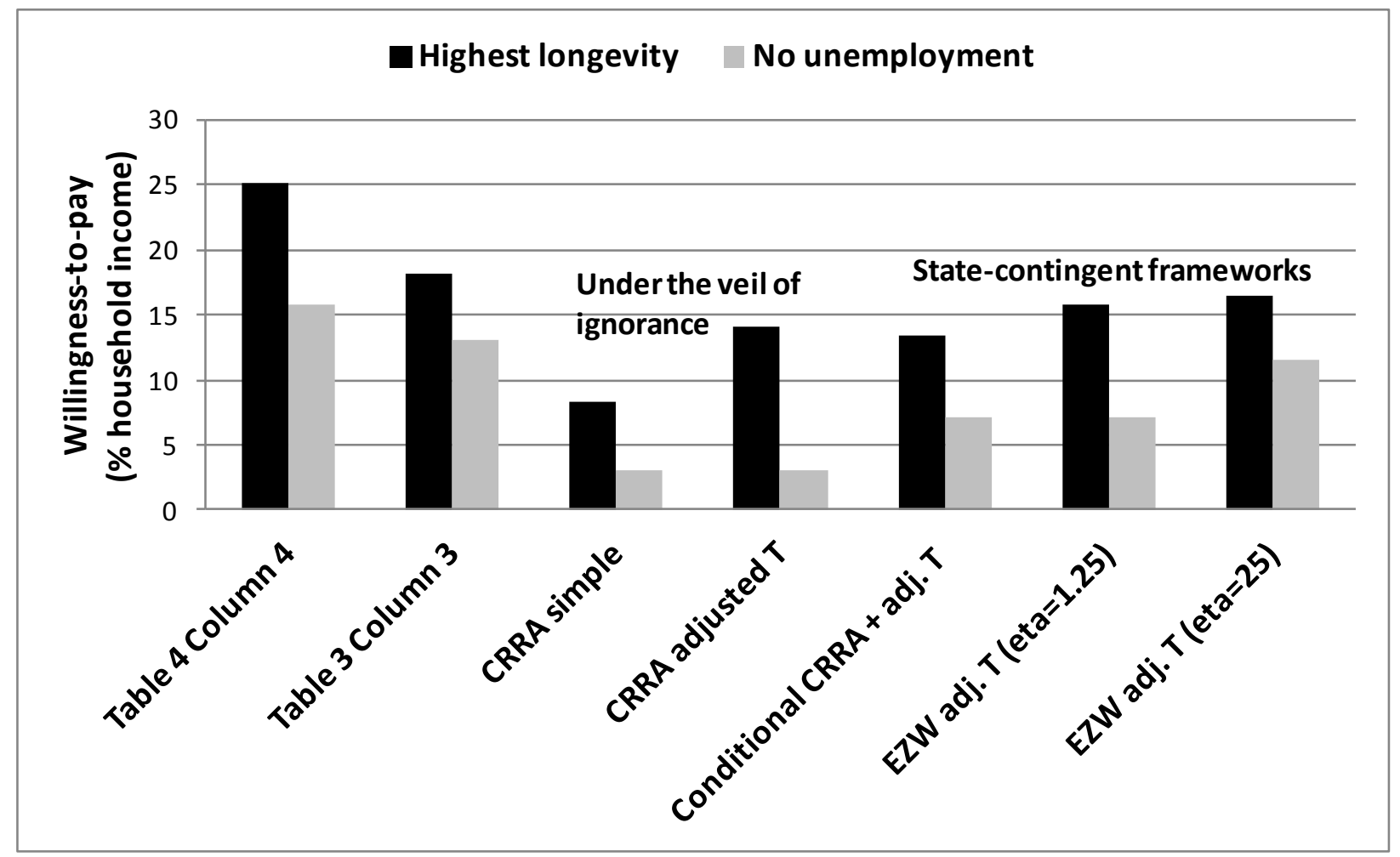

Next, Table 7 and Figure 3 depict the degree of cross-country correlations in the valuation of vital and unemployment risks across the various approaches. As health valuation depends on a single variable, namely longevity, it is not surprising to find very large correlations across the different methodologies. Only the average levels may differ. As the valuation of unemployment depends on both unemployment and the replacement rate, the degree of correlation is somewhat lower. The model-based approach that displays the highest correlations with both subjective valuations is the Epstein-Zin-Weil utility function with low risk aversion. Statecontingent valuations under CRRA utility also deliver comparable correlations with both subjective valuations. However, as shown in Table 6, the CRRA utility does not perform as well matching the levels of average valuations in the sample. 
TABLE 7.-CROSS-COUNTRY CORRELATIONS BETWEEN COMPENSATING DIFFERENTIALS

\begin{tabular}{lcccccc}
\hline \hline & \multicolumn{2}{c}{ Life expectancy } & & \multicolumn{2}{c}{ Unemployment } \\
\cline { 2 - 3 } & Subjective 1 & Subjective 2 & & Subjective 1 & Subjective 2 \\
\hline Subjective 2 & 0.99 & 1 & & 0.78 & 1 \\
CRRA & 0.98 & 0.98 & & 0.4 & 0.7 \\
CRRA adjusted T & 0.97 & 0.98 & & 0.4 & 0.7 \\
CRRA U. flows & $\mathbf{0 . 9 7}$ & $\mathbf{0 . 9 8}$ & & $\mathbf{0 . 7 7}$ & $\mathbf{0 . 8 6}$ \\
Epstein-Zin-Weil low risk aversion & $\mathbf{0 . 9 9}$ & $\mathbf{0 . 9 9}$ & & $\mathbf{0 . 7 6}$ & $\mathbf{0 . 8 7}$ \\
Epstein-Zin-Weil high risk aversion & 0.99 & 0.97 & & 0.45 & 0.62 \\
\hline
\end{tabular}

Figure 3. -SubJective AND Model-Based VALUATIONS OF VITAL AND UNEMPLOYMENT RISKS
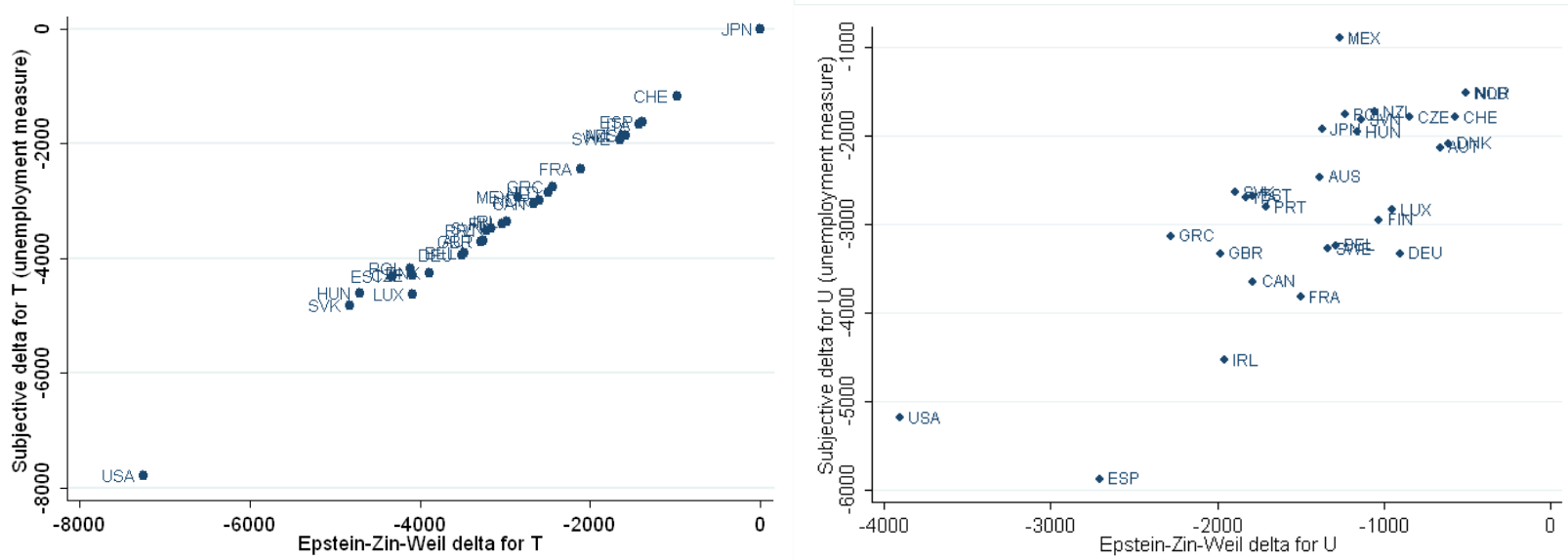

\section{B. Welfare Across OECD Countries}

Figure 4 describes the compensating income differentials for health with respect to those of unemployment across various settings (the two subjective valuations, the state-contingent model-based valuations under both the CRRA framework and Epstein-Zin-Weil with low risk aversion). The United States stands out as an outlier for both risks, as this country is characterized by relatively low longevity, high unemployment (in 2009), low replacement rates, and high income. Countries that consistently display large unemployment compensating differentials are either high-unemployment countries (e.g. ESP, IRL, FRA) or low-replacement rate countries (e.g. 
MEX, CHL, GRC, GBR). Large compensating income differentials for longevity are observed in Russia and Eastern European countries (e.g. SVK, EST, POL).

\section{FiguRE 4.-COMPENSATING INCOME DIFFERENTIALS FOR VITAL AND UNEMPLOYMENT RISKS -} 2009
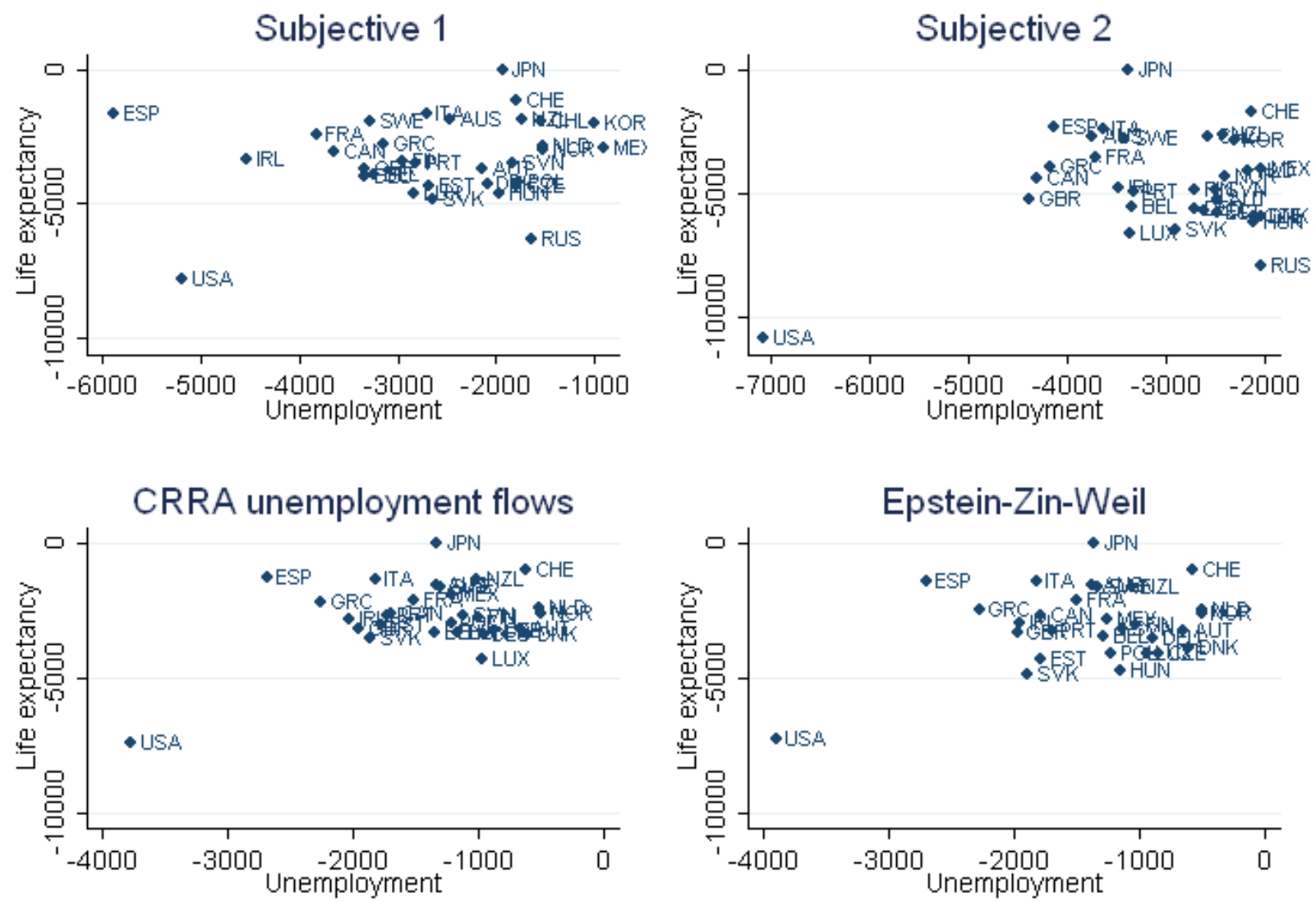

To describe welfare at the country level, we select the estimates from the subjective valuation with an unemployment measure (Table 3 Column 3), which are broadly consistent with Epstein-Zin-Weil valuations.

Figure 5 depicts equivalent incomes among OECD countries, namely the sum of average household income and compensating incomes for the vital and unemployment risks. The correlation between equivalent income and household income is large (0.94) and so is the 
correlation of country ranks (0.93). This reflects the first-order importance of household income on economic welfare. However, the (negative) contributions of compensating incomes to equivalent income are far from being negligible, and sometimes involve large changes in country ranks. A telling example is the United States, which ranks first out of 29 in terms of household income, but only fifth in terms of equivalent income.

Moreover, compensating incomes represent a sizeable proportion of household income, about $30 \%$ on average, and a much higher proportion among lower-income countries. As shown on Figure 6, the sum of longevity and unemployment compensating incomes represents more than $50 \%$ of household income in Estonia, Hungary and Slovakia, where longevity is quite far from OECD standards.

FIGURE 5. -EQUIVALENT INCOMES AMONG OECD COUNTRIES - 2009

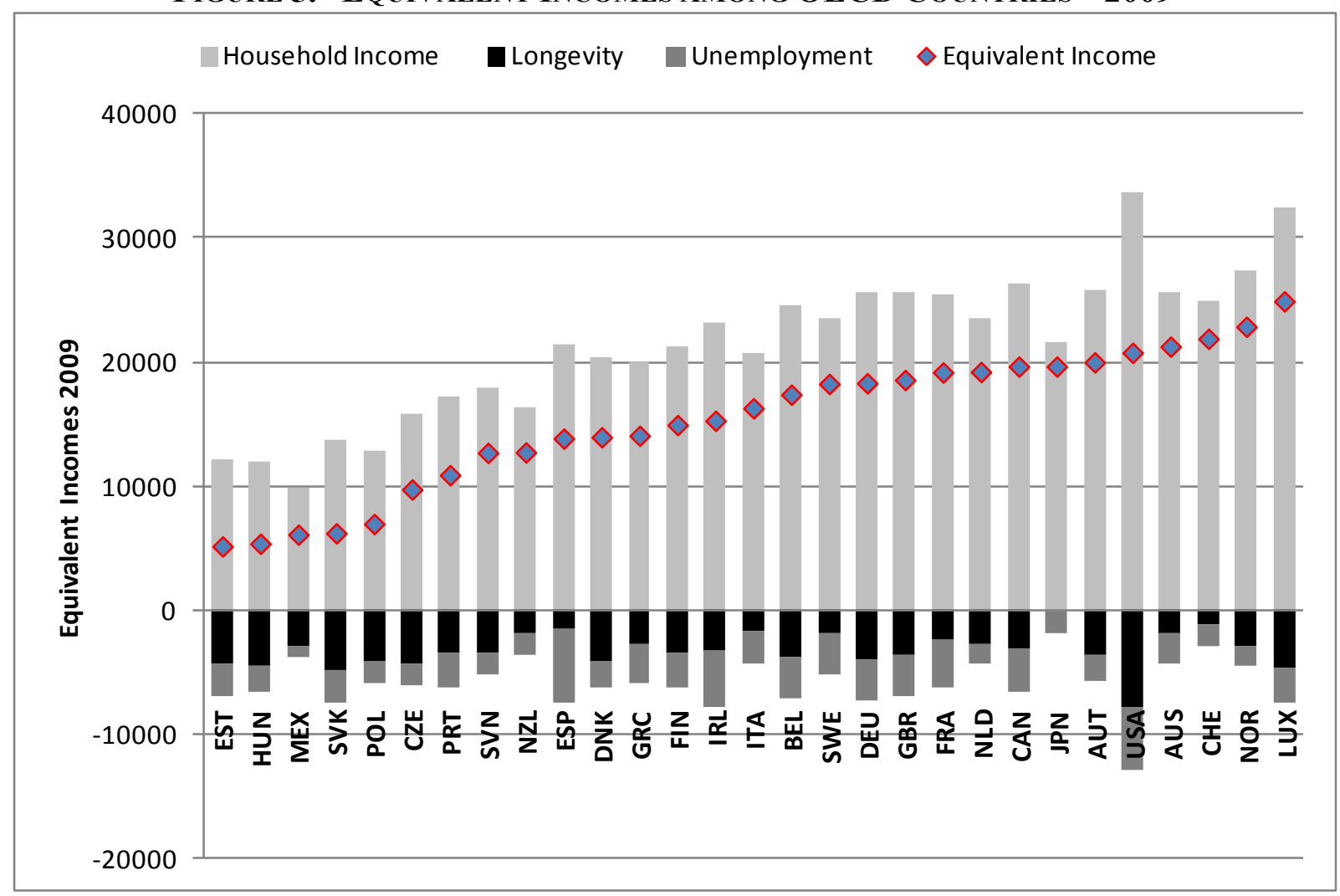


Figure 6. -Sum of Compensating InComes as a Percentage of

HOUSEHOLD DISPOSABLE INCOME

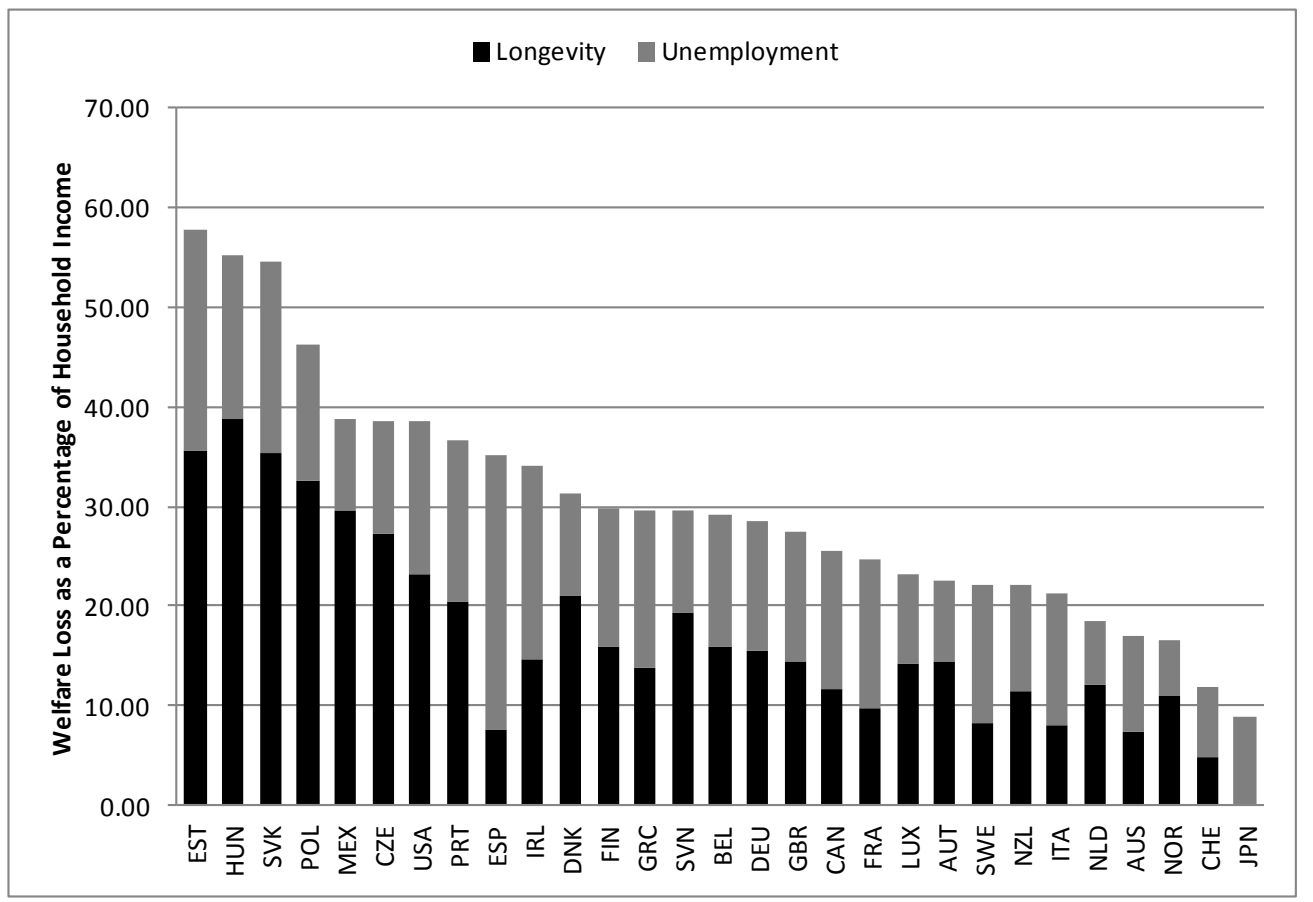

\section{Conclusion}

This paper builds a measure of living standards encompassing household disposable income, unemployment and longevity, while using two different sets of "shadow prices" for nonincome variables. The valuations of vital and unemployment risks estimated from life satisfaction data ("subjective shadow prices") and those derived from model-based approaches and calibrated utility functions ("model-based shadow prices") are shown to be broadly consistent with each other under a set of conditions. Subjective shadow prices appear to be inflated by the downward bias on the income variable in life satisfaction regressions conducted at the individual level, while the latter bias is largely removed when running regressions at the country level. On the other hand, model-based shadow prices are underestimated from: (i) the valuation of the unemployment risk under the veil of ignorance (i.e. for a representative agent); (ii) the use of a constant relative risk aversion utility function that does not disentangle relative risk aversion and the elasticity of 
intertemporal substitution; (iii) calibration issues as the VSL pertains to an adult life rather than the whole life cycle.

This paper paves the way for the construction of series of aggregate living standards among OECD countries, and for the inclusion of inequality (e.g. across educational groups or across gender) in the fundamental dimensions of living standards. Before that, it will be necessary to examine the robustness of shadow prices estimates to various proxy variables (e.g. employment rather than unemployment, health life expectancy rather than life expectancy, etc.), and different econometric methods or life satisfaction databases. This research agenda is currently being pursued in Boarini et al. (2015). 


\section{REFERENCES}

Alberini, A., Loomes, G., Scasny, M. and I. Bateman (2010). Valuation of Environment-Related Health Risks for Children. OECD Publishing, Paris.

Boarini, R., Murtin, F. and P. Schreyer (2015). Inclusive Growth: The OECD Measurement Framework . OECD Statistics Working Papers, No. 64, STD/DOC 2015/6.

Boarini, R., Comola, M., Smith, C., Manchin, R. and F. de Keulenaer (2012). "What Makes for a Better Life?: The Determinants of Subjective Well-Being in OECD Countries - Evidence from the Gallup World Poll”, OECD Statistics Working Papers, 2012/03, OECD Publishing.

Becker, G., T. Philipson and R. Soares (2005). "The Quantity and Quality of Life and the Evolution of World Inequality." American Economic Review, 95 (1): 277-291.

Carroll, C.D., Overland, J. and D. N. Weil (1997). "Comparison Utility in a Growth Model." Journal of Economic Growth, vol.2(4): 339-67.

Carroll, C.D., Overland, J. and D. N. Weil (2000). "Saving and Growth with Habit Formation." American Economic Review, vol. 90(3): 341-55.

Clark, A. and A. Oswald (1994). "Unhappiness and Unemployment". Economic Journal, vol.104(424), pp.648-59.

Clark, A., Frijters, P. and M. Shields (2008); "Relative Income, Happiness and Utility: An Explanation for the Easterlin Paradox and Other Puzzles", Journal of Economic Literature, Vol.46, no.1, pp.95-144.

Cordoba, J. C. and M. Ripoll (2013). "Beyond Expected Utility in the Economics of Health and Longevity.” Mimeo.

Cordoba, J. C. and G. Verdier (2008). "Inequality and Growth: Some Welfare Calculations." Journal of Economic Dynamics and Control, 32(6): 1812-1829. 
Day, J. H., K. Miyamura, A. D. Grant, A. Leeuw, J. Munsamy, R. Baggaley and G. J. Churchyard (2003). "Attitudes to HIV voluntary counseling and testing among mineworkers in South Africa: Will availability of antiretroviral therepy encourage testing?" AIDS CARE: Psychological and Socio-medical Aspects of AIDS/HIV, 15 (5): 665-672.

Deaton, A. (2008). "Income, Health, and Well-Being around the World: Evidence from the Gallup World Poll." Journal of Economic Perspectives, 22(2): 53-72.

Decancq, K., Fleurbaey, M. and F. Maniquet (2015). "Multidimensional poverty measurement with individual preferences," CORE Discussion Papers 2015008, Université catholique de Louvain, Center for Operations Research and Econometrics (CORE).

Di Tella R., R. MacCulloch, A. Oswald, (2003), "The Macroeconomics of Happiness", The Review of Economics and Statistics, 85 (4), pp. 809-827.

Dockins, C., Maguire, K. , Simon N. and M. Sullivan (2004). Value of statistical life analysis and environmental policy: A white paper. Prepared by the National Center for Environmental Economics, US Environmental Protection Agency, for Presentation to the Environmental Economics Advisory Committee of the Science Advisory Board.

Easterlin R.A. (1974). "Does economic growth improve the human lot? Some empirical evidence", in P.A. David, M.W. Reder (eds.), Nations and Households in Economic Growth: Essays in Honor of Moses Abramovitz, New York: Academic Press.

Easterlin R.A. (1995), “Will raising the incomes of all increase the happiness of all?", Journal of Economic Behaviour and Organization, vol.27 pp.35-48.

Epstein, L., and S. E. Zin (1989). "Risk Aversion, and the Temporal Behavior of Consumption Growth and Asset Returns: A Theoretical Framework." Econometrica, vol.57 (4), 937-969. 
Epstein, L. and S. E. Zin (1991). "Substitution, Risk Aversion, and the Temporal Behavior of Consumption and Asset Returns: An Empirical Analysis." Journal of Political Economy, vol.99 (2), pp.263-286.

Fleurbaey, M. (2009). "Beyond GDP: The Quest for a Measure of Social Welfare." Journal of Economic Literature, vol.47 (4): 1029-1075.

Fleurbaey, M. and D. Blanchet (2013). "Beyond GDP: Measuring Welfare and Assessing Sustainability". Mimeo.

Frey, B. and A. Stutzer (2000). "Happiness, Economy and Institutions". Economic Journal, vol.110(446), pp.918-38.

Fujiwara, D. (2013). “A general method for valuing non-market goods using wellbeing data: Three-stage wellbeing valuation", Mimeo.

Fujiwara, D. and R. Campbell (2011)."Valuation Techniques for Social Cost-Benefits Analysis", HM Treasury Discussion Paper.

Gaulier, G. and M. Fleurbaey (2009). "International Comparisons of Living Standards by Equivalent Incomes." Scandinavian Journal of Economics, vol.111 (3) pp.597-624.

Hall, R. and C.I. Jones (2007). "The Value of Life and the Rise in Health Spending". The Quarterly Journal of Economics (2007), vol.122 (1): 39-72.

Helliwell, J. F. and Barrington-Leigh, C. P. (2010). "Viewpoint: Measuring and understanding subjective well-being." Canadian Journal of Economics/Revue canadienne d'économique, 43: 729-753.

Hammitt, J. K. and K. Haninger (2010), "Valuing Fatal Risk to Children and Adults: Effects of Disease, Latency and Risk Aversion”. Journal of Risk and Uncertainty, Vol. 40, pp. 57-83. ILO (2009). ILO Social Security Inquiry database.

Jones, C. and P. Klenow (2011). "Beyond GDP? Welfare Across Countries and Time." Mimeo. 
Kahneman, D., Knetsch, J. and R. H. Thaler (1991). "The Endowment Effect, Loss Aversion, and Status Quo Bias: Anomalies.” Journal of Economic Perspectives, vol.5(1): 193-206.

Kahneman, D., and A. B. Krueger (2006). "Developments in the Measurement of Subjective Well-Being." Journal of Economic Perspectives, 20(1): 3-24.

Ljungqvist, L., and H. Uhlig (2000). “Tax Policy and Aggregate Demand Management under Catching Up with the Joneses.” American Economic Review, vol.90(3): 356-66.

Murphy, K. M. and R. Topel (2006). "The Value of Health and Longevity.” Journal of Political Economy, 114(5): 871-904.

Murtin, F., De Serres, A. and A. Hijzen (2013). "The Ins and Outs of Unemployment: The Role of Labour Market Institutions", OECD Economics Department Working Paper, Forthcoming.

Murtin, F. and J.M. Robin (2013). "Labour Market Reforms and Unemployment Dynamics", Mimeo.

OECD (2010). Employment Outlook; OECD Publishing, Paris.

OECD (2011). How's Life? Measuring Well-being; OECD Publishing, Paris.

OECD (2013a). Guidelines on measuring subjective well-being; OECD Publishing, Paris.

OECD (2013b). OECD Income Distribution Database.

OECD (2013c). OECD online database.

Pollak, R. A. (1976). “Interdependent Preferences.”American Economic Review, vol.66(3) pp. 309-20.

Powdthavee, N. (2010). "How Much Does Money Really Matter? Estimating the Causal Effects of Income on Happiness", Empirical Economics, vol.39(1), pp.77-92.

Samuelson P.A. (1956). "Social Indifference Curves”, Quarterly Journal of Economics, vol.70: 1.22 . 
Samuelson P.A. (1961). "The evaluation of "social income": Capital formation and wealth", in F.A. Lutz and D.C. Hague (eds.), The Theory of Capital, London: Macmillan.

Samuelson P.A. (1974). "Complementarity: An essay on the 40th anniversary of the Hicks-Allen revolution in demand theory", Journal of Economic Literature, vol.12 pp.1255.1289.

Stevenson, B. and J. Wolfers (2013). "Subjective Well-being and Income: Is there any Evidence of Satiation?" American Economic Review, Papers and Proceedings, vol.101(3) 598-604.

Stutzer, A. and R. Lalive (2004). "The Role of Social Work Norms in Job Searching and Subjective Well-Being," Journal of the European Economic Association, vol. 2(4), pp.696$719,06$.

Viscusi, W. K. and J. Aldy (2003). "The Value of a Statistical Life: A Critical Review of Market Estimates Throughout the World." The Journal of Risk and Uncertainty, vol.27 (1): 5-76.

Weil, P. (1990). "Nonexpected Utility in Macroeconomics." Quarterly Journal of Economics, vol.105(1): pp.29-42.

Wexler, N. S. (1979). “Genetic 'Russian Roulette': The Experience of Being At Risk for Huntington's Disease”. In Genetic Counseling: Psychological Dimensions. S. Kessler (ed.). New York Academic Press.

World Bank (2013). World Development Indicators, online database.

Wunder, C., Wiencierz, A., Schwarze, J. and H. Küchenhoff (2013), "Well-Being over the Life Span: Semiparametric Evidence from British and German Longitudinal Data", Review of Economics and Statistics, vol. 95, No. 1: 154-167.

Yaniv, I., D. Benador and M. Sagi (2004). "On not wanting to know and not wanting to inform others: choices regarding predictive genetic testing." Risk Decision and Policy, vol.9: 317336. 


\section{Appendix}

\section{A.1. Derivation of Unemployment Risk Measures}

Consider the following utility representation and life satisfaction definition:

$$
\begin{gathered}
u(y, U N, T)=E(\tilde{y})(1+\lambda C V(\tilde{y})) \exp (\gamma T) \text { with } \lambda<0, \\
L S=a+\alpha \log (u(y, U N, T))+\varepsilon,
\end{gathered}
$$

and denote $y=E(\tilde{y})$, which is equal to employment income $y(e)$ with probability $(1-U N)$ and to $\tau \cdot y(e)$ with probability $U N$ (where $U N$ is the unemployment rate, while $\tau$ denotes the replacement rate). Average income satisfies $y=y(e)(1-U N+U N \cdot \tau)$, while the variance of $\tilde{y}$ is equal to $(y(e))^{2}(1-U N)+\tau^{2}(y(e))^{2} U N-y^{2}$. Using these facts, algebraic manipulation implies the following expression for the coefficient of variation of income:

$$
C V(\tilde{y})=\frac{1-\tau}{1-U N+U N \cdot \tau}\left(U N-U N^{2}\right)^{1 / 2}
$$

Taking logs of utility $u(y, U N, T)$ and using $y=E(\tilde{y})$ yields:

$$
L S=a+\alpha[\log (y)+\log (1+\lambda C V(\tilde{y}))+\gamma T]+\varepsilon .
$$

Empirically, the distribution of $C V(\tilde{y})$ across countries and time has mean 0.12 and standard deviation 0.06. It can reasonably be viewed as small, and one hypothesizes that the following approximation holds: $\log (1+\lambda C V(\tilde{y})) \approx \lambda C V(\tilde{y})$. This hypothesis appears to be valid as the relative elasticity of $C V(\tilde{y})$ in table 3 column 3 is equal to $-3.823 / 3.893$ so that $\lambda \approx-1$, confirming that $\lambda C V(\tilde{y})$ is relatively small. The specification of the regression depicted in Table 3 column 3 follows.

\section{A.2. $\quad$ Solutions for State-Contingent Valuations Under CRRA Utility with Intercept}

This section derives state-contingent valuations for the case of CRRA utility with 
intercept. Indirect utility functions are given by:

$$
\begin{aligned}
& w(e)=\tilde{u}(c(e))+\beta \pi[\rho(e) w(e)+(1-\rho(e)) w(u)] \\
& w(u)=\tilde{u}(c(u))+\beta \pi[\rho(u) w(e)+(1-\rho(u)) w(u)] .
\end{aligned}
$$

This is a system of two linear equations in two unknowns, $w(u)$ and $w(e)$. Subtracting one from the other:

$$
w(e)-w(u)=\tilde{u}(c(e)-\tilde{u}(c(u))+\beta \pi[(\rho(e)-\rho(u))(w(e)-w(u))]
$$

or

$$
w(e)-w(u)=\frac{\tilde{u}(c(e))-\tilde{u}(c(u))}{1-\beta \pi(\rho(e)-\rho(u))}
$$

Plugging this result into $w(u)$ yields

$$
w(u)=\frac{1}{1-\beta \pi}\left[\frac{\tilde{u}(c(u))(1-\beta \pi \rho(e))+\beta \pi \rho(u) \tilde{u}(c(e))}{1-\beta \pi(\rho(e)-\rho(u))}\right],
$$

which also implies

$$
w(e)=\frac{1}{1-\beta \pi}\left[\frac{\tilde{u}(c(e))(1-\beta \pi(1-\rho(u)))+\beta \pi(1-\rho(e)) \tilde{u}(c(u))}{1-\beta \pi(\rho(e)-\rho(u))}\right] .
$$

\section{A.3. Special Case for Epstein-Zin-Weil Utility Function with $\boldsymbol{\sigma}=\boldsymbol{\eta}$}

Although the general Epstein-Zin-Weil model described above does not admit a closedform solution, one exists for the case in which $\sigma=\eta$, which we adopt as a benchmark case. Since in the calibration $\sigma<\eta$, the case $\sigma=\eta$ corresponds to a lower bound on the willingness to pay for the elimination of unemployment risk, as values $\eta>\sigma$ are needed to generate more substantial premiums.

In this special case, welfare for an unemployed individual is given by 


$$
w(u)=\frac{1}{1-\tilde{\beta}(\pi)} \frac{c(u)^{1-\sigma}}{1-\sigma}\left[\frac{1-\tilde{\beta}(\pi)\left(\rho(e)-\rho(u) \tau^{\sigma-1}\right)}{1-\tilde{\beta}(\pi)(\rho(e)-\rho(u))}\right],
$$

while that for the employed individual is

$$
w(e)=\frac{1}{1-\tilde{\beta}(\pi)} \frac{c(e)^{1-\sigma}}{1-\sigma}\left[\frac{1-\tilde{\beta}(\pi)\left(1-\rho(u)-\tau^{1-\sigma}(1-\rho(e))\right)}{1-\tilde{\beta}(\pi)(\rho(e)-\rho(u))}\right] .
$$

Notice that in the absence of unemployment, individual lifetime utility would reduce to

$$
w(c)=\frac{1}{1-\tilde{\beta}(\pi)} \frac{c^{1-\sigma}}{1-\sigma}
$$

which corresponds to the present value of all future utility flows discounted at the effective rate $\tilde{\beta}(\pi)$. Thus the terms in brackets in the equations for $w(u)$ and $w(e)$ above capture the additional effect of unemployment risk on individual welfare.

Aggregate welfare in the case $\sigma=\eta$ is given by

$$
w(y)=(1-U N) \cdot w(e)+U N \cdot w(u)
$$

which reduces to the following simple expression

$$
w(y)=\frac{1}{1-\tilde{\beta}(\pi)} \frac{y^{1-\sigma}}{1-\sigma} \frac{1-U N+U N \cdot \tau^{1-\sigma}}{(1-U N+U N \cdot \tau)^{1-\sigma}} .
$$

Similarly, closed form solutions can be obtained for the health and unemployment premiums, which are given by

$$
\begin{gathered}
\delta^{T}=y\left[\left(\frac{1-\tilde{\beta}\left(\pi^{*}\right)}{1-\tilde{\beta}(\pi)}\right)^{\frac{1}{1-\sigma}}-1\right], \\
\delta^{U}=y\left[\frac{\left(1-U N+U N \cdot \tau^{1-\sigma}\right)^{\frac{1}{1-\sigma}}}{1-U N+U N \cdot \tau}-1\right] .
\end{gathered}
$$

As expected, the unemployment equivalent income is equal to the one derived with a CRRA utility function. 